\title{
Ajuste de funções matemáticas de crescimento aos números de casos de pessoas contaminadas com o COVID-19 no Brasil: uma abordagem para o ensino médio
}

Adjustment mathematical growth functions to the number of cases of people infected with COVID19 in Brazil: an approach to high school

Ajuste de las funciones de crecimiento matemático al número de casos de personas infectadas por

COVID-19 en Brasil: una aproximación a la escuela secundaria

\section{Resumo}

A matemática é aplicada em vários campos do conhecimento humano, ou seja, conceitos e procedimentos matemáticos são usados para resolver problemas nas mais diversas áreas do conhecimento. Por exemplo, a compreensão de funções de crescimento é um pré-requisito necessário para aprender muitos conceitos em estudos epidemiológicos. Com o advento do novo coronavírus, um grande número de dados é gerado sobre a quantidade de pessoas contaminadas e mortas. A análise funcional desses dados é necessária para se entender o comportamento do quadro pandêmico da COVID-19. Sendo assim, e dentro desse contexto, o objetivo deste artigo foi mostrar como as funções matemáticas de crescimento podem ser utilizadas para a análise de dados científicos a partir dos conteúdos do Ensino Médio, com foco no número de casos de pessoas contaminadas com a COVID-19 no Brasil. Para tanto, utilizou-se de uma pesquisa quantitativa exploratória de dados importados da Plataforma Integrada de Vigilância em Saúde do Ministério da Saúde do Brasil, especificamente, no Painel Coronavírus dos casos da doença em 2019 atualizados até julho de 2021 e realizando o ajuste dos dados usando as funções exponencial, potência e polinomial, conteúdos trabalhados na disciplina de Matemática no Ensino Médio. Utilizou-se também o aplicativo Construct que demonstrou a relevância do isolamento e do distanciamento social no combate ao COVID-19. Os resultados mostraram que as funções potência, exponencial e polinomial podem ser utilizadas para estudar o número de casos de 
pessoas contaminadas com o COVID-19. Por outro lado, a função polinomial apresentou melhor ajuste aos dados do que as funções potência e exponencial. O uso do aplicativo Construct mostrou que jogos digitais é uma excelente ferramenta para se estudar fenômenos epidemiológicos no ensino médio.

Palavras-chave: Pandemia; Análise funcional; Modelagem matemática; Modelagem computacional; Jogos digitais.

\begin{abstract}
Mathematics is applied in several fields of human knowledge, that is, mathematical concepts and procedures are used to solve problems in the most diverse areas of knowledge. For example, an understanding of growth functions is a necessary prerequisite for learning many concepts in epidemiological studies. With the advent of the new coronavirus, a great deal of data is generated on the number of people infected and killed. The functional analysis of these data is necessary to understand the behavior of the COVID-19 pandemic scenario. Therefore, and within this context, the aim of this article was to show how the mathematical growth functions can be used for the analysis of scientific data from the contents of high school, focusing on the number of cases of people infected with COVID-19 in Brazil. For this purpose, an exploratory quantitative survey of data imported from the Integrated Health Surveillance Platform of the Ministry of Health of Brazil was used, specifically, in the Coronavirus Panel of disease cases in 2019, updated until July 2021 and performing the adjustment of the data using the exponential, power and polynomial functions, contents worked in the subject of mathematics in high school. The Construct application was also used, which demonstrated the relevance of isolation and social distancing in the fight against COVID-19. The results showed that the power, exponential and polynomial functions can be used to study the number of cases of people infected with COVID-19. On the other hand, the polynomial function presented better fit to the data than the power and exponential functions. The use of the Construct application showed that digital games are an excellent tool to study epidemiological phenomena in high school.
\end{abstract}

Keywords: Pandemic; Functional analysis; Mathematical modeling; Computational modeling; Digital games.

\begin{abstract}
Resumen
Las matemáticas se aplican en varios campos del conocimiento humano, es decir, se utilizan conceptos y procedimientos matemáticos para resolver problemas en las más diversas áreas del conocimiento. Por ejemplo, la comprensión de las funciones de crecimiento es un requisito previo necesario para aprender muchos conceptos en estudios epidemiológicos. Con la llegada del nuevo coronavirus, se genera una gran cantidad de datos sobre la cantidad de personas infectadas y asesinadas. El análisis funcional de estos datos es necesario para comprender el comportamiento del escenario pandémico COVID-19. Por tanto, y dentro de este contexto, el objetivo de este artículo fue mostrar cómo las funciones matemáticas de crecimiento se pueden utilizar para el análisis de datos científicos de los contenidos del bachillerato, centrándose en el número de casos de personas infectadas por COVID-19 en Brasil. Para ello, se utilizó una encuesta cuantitativa exploratoria de datos importados de la Plataforma Integrada de Vigilancia en Salud del Ministerio de Salud de Brasil, específicamente, en el Panel de casos de enfermedad de Coronavirus en 2019, actualizado hasta julio de 2021 y realizando el ajuste de los datos. utilizando las funciones exponencial, potencia y polinomio, contenidos trabajados en la asignatura de matemáticas en el bachillerato. También se utilizó la aplicación Construct, que demostró la relevancia del aislamiento y el distanciamiento social en la lucha contra el COVID-19. Los resultados mostraron que las funciones de potencia, exponencial y polinomial se pueden utilizar para estudiar el número de casos de personas infectadas con COVID-19. Por otro lado, la función polinomial presentó un mejor ajuste a los datos que las funciones potencia y exponencial. El uso de la aplicación Construct mostró que los juegos digitales son una excelente herramienta para estudiar fenómenos epidemiológicos en la escuela secundaria.
\end{abstract}

Palabras clave: Pandemia; Análisis funcional; Modelo matemático; Modelado computacional; Juegos digitales.

\title{
1. Introdução
}

A matemática tem estado sob os holofotes, desde o início da pandemia do Covid-19 que se espalhou pelo mundo com consequências devastadoras. Ao abrir qualquer site de notícias, é possível observar gráficos e tabelas como nunca antes. O crescimento exponencial está se tornando famoso à medida que os casos dobram e um único portador pode levar a enormes cadeias de infecção com o novo patógeno. Com o advento da pandemia do Covid-19, expressões como achatamento da curva, números de pessoas contaminadas, números de pessoas recuperadas, crescimento exponencial, modelos matemáticos e análise de dados fazem parte do nosso cotidiano. Por outro lado, especialistas como Marcelo Viana (2020), diretor-geral do Instituto de Matemática Pura e Aplicada (Impa), considerou que, no geral, o povo brasileiro tem muita dificuldade em entender conceitos matemáticos relacionados com a pandemia do COVID-19 (Viana, 2020). Para ele, a pandemia do novo coronavírus (COVID-19) revelou a fragilidade do ensino de matemática no Brasil. Nesse contexto, a grande maioria da população 
brasileira desconhecia a linguagem matemática básica revelada através da divulgação dos dados estatísticos de pessoas contaminadas com o novo patógeno.

Além disso, Viana (2020) afirmou que a nossa dificuldade em entender e aplicar tais conceitos é mais uma evidência de que a forma como se aprende matemática na escola está muito longe de nos preparar para usar a disciplina na vida real. Ele considerou também que, existe entre os estudantes brasileiros um analfabetismo de dados. Assim, ser alfabetizado em dados significa ser capaz de entender números, gráficos, probabilidades ou questões lógicas, por exemplo, e conseguir usar esses dados para entender padrões ou tomar decisões. Modelos matemáticos epidemiológicos é um recurso didático muito importante que pode ser abordado eficientemente no ensino médio. Para tanto, basta o aluno aprender os tipos básicos das funções polinomiais e transcendentes. Os próprios dados provenientes da pandemia do COVID-19 no Brasil podem ser utilizados para ensinar os alunos a manipular dados, ajustar curvas e obter a função matemática correspondente de todo o processo de análise. Tudo isso é fundamental para se ter um ensino contextualizado.

O contexto ajuda os alunos a fazer interações de temas do cotidiano para um contexto significativo e relevante. A contextualização do conteúdo e dos conceitos no ensino de matemática ajuda a melhorar a motivação, o aprendizado e a persistência do aluno. Segundo Krause, Waters e Stuart (2016), os processos cognitivos agem para alcançar a aprendizagem por meio de mudança conceitual com base em três princípios fundamentais ${ }^{1}$, que formam o tripé da aprendizagem eficaz: (1) identificar o conhecimento prévio dos alunos para informar a instrução; (2) envolver os alunos na promoção de mudanças conceituais para que possam construir um conhecimento profundo organizado em uma estrutura conceitual; e (3) encorajar a metacognição para construir hábitos de alunos especialistas que definem seus objetivos de aprendizagem e monitoram seu próprio progresso. A questão da pesquisa é: "Qual é o papel e o impacto da contextualização do conteúdo no que diz respeito à atitude, desempenho e persistência do aluno?"

A contextualização no ensino de matemática é uma das chaves para envolver os alunos no processo de ensinoaprendizagem, onde eles podem relatar suas experiências de vida em sala de aula. Isso torna a aula significativa e relevante para a vida dos alunos, relacionando o contexto vivenciado por eles com o conteúdo matemático ensinado na escola. O "ensinar matemática" dentro de certo contexto é bastante desafiador para o professor, pois envolvem problemas relacionados com a própria forma de ensinar a matemática, incluindo as dificuldades na interpretação de afirmações matemáticas, conflito na análise da aula, falta de interações robustas com as experiências vivenciadas pelos alunos e aulas de conteúdos altamente abstratos. O conhecimento dos professores também pode ser um problema, uma vez que nem todos os professores têm a capacidade de contextualizar sua lição e criar uma aprendizagem significativa no ensino de matemática (Reyes, et al., 2019).

O ensino centrado no contexto significa práticas relacionadas às experiências, situações e atividades da vida real que dão sentido à aula de matemática. A contextualização ocorre quando os materiais e métodos de ensino estão vinculados às experiências e ao ambiente dos alunos. O uso de materiais e informações locais no ensino ajuda os alunos a entender completamente os conceitos matemáticos expostos em sala de aula (Reyes, et al., 2019).

Segundo Reyes et al. (2019), as atribuições em sala de aula impactam os alunos, orientando sua atenção em relação às partes específicas da matemática e indicando abordagens para processar dados. A diretriz de contextualização concentra-se nas inter-relações entre as ideias. Esta é mais uma direção do que um assunto específico que enfatiza a introdução e revisão dos dados, mas não realmente as associações entre eles. Da mesma forma, contextualizar a direção faz com que os alunos

${ }^{1}$ Para o primeiro princípio, o conhecimento prévio, demonstra que a instrução com conteúdo contextualizado pode ativar o conhecimento prévio dos alunos e promover uma resolução mais eficaz de problemas. Certamente, relacionar temas com a vida diária dos alunos ajudam a reter melhor as informações. Para o segundo princípio, promover a mudança conceitual, a contextualização do conteúdo em atividades de engajamento em sala de aula interativa que motiva os alunos com a relevância de um conceito, melhora significativamente o aprendizado. Para o terceiro princípio, promovendo a metacognição, a contextualização do conteúdo ajuda os alunos a refletir sobre seu aprendizado para unir ideias de um contexto concreto familiar de um conceito abstrato, para que possam reconhecer sua própria relação pessoal com esses conceitos (Krause et al., 2016). 
organizem e incorporem o aprendizado, conectando-se com os pensamentos lógicos a partir de vários pontos de vista, enquanto buscam respostas para questões importantes (Reyes, et al., 2019).

Assim, o ensino contextualizado é aceito para antecipar a transferência de pensamentos matemáticos para diferentes ambientes, uma vez que os alunos descobrem como relacionar o plano de conteúdo a questões e circunstâncias significativas em suas vidas. A contextualização rica destaca a revisão avançada da memória e, ao longo dessas linhas, a transferência (Reyes, et al., 2019). Além disso, a contextualização da instrução conecta-se aos alunos na utilização dinâmica de seus entendimentos lógicos. Adaptação dinâmica, em vez de reunião passiva, é necessária para os alunos desenvolverem a compreensão do uso de seu insight sob várias condições. A aprendizagem dinâmica em vários ambientes é garantida para ajudar a abstração de informações e, desta forma, a transferência de pensamentos matemáticos para diversos frameworks.

No Brasil, em 2010, o Conselho Nacional de Educação (CNE) promulgou novas Diretrizes Curriculares Nacionais (DCN), ampliando e organizando o conceito de contextualização como "a inclusão, a valorização das diferenças e o atendimento à pluralidade e à diversidade cultural resgatando e respeitando as várias manifestações de cada comunidade" (Brasil, 2021a):

Com base nos recentes documentos curriculares brasileiros, a BNCC leva em conta que os diferentes campos que compõem a matemática reúnem um conjunto de ideias fundamentais que produzem articulações entre eles: equivalência, ordem, proporcionalidade, interdependência, representação, variação e aproximação. Essas ideias fundamentais são importantes para o desenvolvimento do pensamento matemático dos alunos e devem se converter, na escola, em objetos de conhecimento.

Assim, de acordo a Base Nacional Comum Curricular (BCNN) (Brasil, 2021a), a contextualização no ensino da matemática é elemento fundamental para que haja a transferência de pensamentos matemáticos para diversos frameworks.

No ensino médio da matemática, os estudos das funções são vias importantes para se intensificar o processo de contextualização em sala de aula. Mesmo que os alunos não percebam, as funções fazem parte do nosso cotidiano. Por exemplo, uma relação funcional entre as quantidades está sempre relacionada quando pagamos pela gasolina por litro ou fruta por real. Precisamos de funções para entendermos planos financeiros, com a finalidade de se calcular coisas como receita acumulada e juros. As funções também são importantes para interpretações da demografia local e mundial e do crescimento populacional, que são essenciais para o planejamento e desenvolvimento econômico. Funções são encontradas até mesmo em configurações bastante comuns como estatísticas de futebol e conversações sobre política. As ferramentas algébricas nos permitem expressar essas relações funcionais de maneira muito eficiente.

À medida que as relações funcionais se tornam mais complexas, como no crescimento de uma população ou no acúmulo de juros ao longo do tempo, as soluções não são calculadas com tanta facilidade porque a base muda a cada período. Nessas situações, as ferramentas algébricas permitem que problemas altamente complexos sejam resolvidos e exibidos de uma forma que forneça uma imagem poderosa de mudança ao longo do tempo. Como os alunos têm muitos encontros com relações funcionais em suas vidas diárias, eles trazem uma grande quantidade de conhecimento relevante para a sala de aula. Esse conhecimento pode ajudar os alunos a raciocinar cuidadosamente sobre os problemas de álgebra. Assim, um problema descrito em sua manifestação cotidiana pode ser resolvido por muito mais alunos do que o mesmo problema apresentado apenas como uma equação matemática. No entanto, se os conhecimentos de matemática existentes que os alunos trazem para a sala de aula não estão vinculados ao aprendizado formal de álgebra, eles não estarão disponíveis para apoiar um novo aprendizado (Donovan \& Bransford, 2005).

Uma "função" é formalmente definida em matemática como "um conjunto de pares ordenados de números $(x, y)$ de modo que a cada valor da primeira variável $(x)$ corresponde a um valor único da segunda variável $(y)$ ). Tal definição, embora verdadeira, não indica aos alunos que eles estão começando a aprender sobre uma nova classe de problemas em que o valor de 
uma coisa é determinado pelo valor de outra e a regra que diz a eles como estão relacionados (Donovan \& Bransford, 2005). Esses autores afirmaram que, "na educação matemática, a função passou a ter uma interpretação mais ampla que se refere não apenas à definição formal, mas também às múltiplas maneiras pelas quais as funções podem ser escritas e descritas. Formas comuns de descrever funções incluem tabelas, gráficos, símbolos algébricos, palavras e situações problemáticas. Cada uma dessas representações descreve como o valor de uma variável é determinado pelo valor de outra".

Numa época em que a quantidade de dados cresce exponencialmente, os estudos de funções matemáticas tornam-se extremamente necessários nas escolas, com a finalidade de ajudar os alunos a entender a maneira como os acontecimentos do dia a dia estão relacionados com suas experiências de vida. Por exemplo, a pandemia do novo coronavírus tem sido uma grande crise sanitária e humanitária, que tem resultado em milhares de mortes em todo mundo. Um tema importante como esse não pode ficar ausente dos debates nas escolas. Tópicos matemáticos importantes como o aumento no número de casos de pessoas contaminadas com o COVID-19, estão intrinsicamente relacionados com as funções de crescimento. Isso é uma excelente oportunidade para que os professores de matemática possam relacionar os estudos de funções com os números de casos de crescimento de pessoas contaminadas com o COVID-19. O crescimento do número de casos durante a pandemia do COVID-19, fez com que a matemática se tornasse a medida não farmacológica mais importante no combate à disseminação do patógeno no mundo. Ao estudar o comportamento funcional do número de casos de contaminação com o COVID-19, os alunos serão capazes de entender as bases epidemiológicas de como o patógeno será disseminado dentro da população, e se tornarão eles próprios agentes educacionais de divulgação de medidas de contenção sanitária.

Em todos os processos de análises de dados, é importante que eles sejam obtidos de fontes fidedignas, para evitar discussões espúrias de informações. Sendo assim, por ser um tema atual e de grande divulgação na mídia, os dados oriundos de pessoas contaminadas com o COVID-19 no Brasil é uma excelente ferramenta de estudos matemáticos, não apenas para a divulgação estatística, mas, para o aprendizado no ensino médio com foco no estudo de funções matemáticas de crescimento. Além dos conhecimentos matemáticos inerentes ao estudo das funções, a manipulação e a análise de dados sobre o COVID-19 no Brasil mostram que a contextualização é extremamente necessária no processo ensino-aprendizagem do ensino médio.

A forma prática, com dados do cotidiano dos alunos, ajuda a estimular o aprendizado da matemática estatística na escola. Uma pequena mudança de paradigma acrescenta novas perspectivas de ensino muito além do algebrismo desconexo. Com o advento de tantas informações, é necessário que os professores abordem em suas aulas temas atuais objetivando maior dinamismo entre os estudantes. Atualmente, a data science é uma grande aliada para estimular os alunos do ensino médio no aprendizado da matemática. Usada conjuntamente com um aplicativo computacional, como o Excel, por exemplo, é possível introduzir os princípios básicos da data science na escola, com a execução de pequenas tarefas, tais como o estudo de funções matemáticas.

Analisar dados não é uma tarefa fácil, entretanto, a ciência de dados (Data Science) pode ser utilizada com grande eficiência no ensino médio nas aulas de matemática como elemento motivador para os estudantes. Embora o jargão da ciência de dados já esteja circulando há algum tempo, poucas pessoas sabem sobre o real propósito de ser um cientista de dados. O principal objetivo da Data Science é encontrar padrões nos dados. Ele usa várias técnicas estatísticas para analisar e extrair percepções dos dados. Desde a extração, conversão e pré-processamento de dados, um cientista de dados deve examinar os dados minuciosamente e fazer previsões a partir deles. O objetivo de um cientista de dados é tirar conclusões dos dados. Por meio dessas conclusões, ele pode ajudar as instituições a tomar decisões mais inteligentes. O cientista de dados é bem versado na solução de problemas, sendo designado para encontrar padrões nos dados. Seu objetivo é reconhecer amostras redundantes e extrair insights delas ${ }^{2}$.

${ }^{2} \mathrm{~A}$ Data Science é a integração entre a ciência da computação e a matemática, com a finalidade de analisar e simular todos os tipos de dados nas mais diferentes áreas do conhecimento humano. Antes da Data Science, tínhamos os estatísticos. Esses estatísticos experientes eram 
O ensino a partir dos princípios da Data Science também promovem a alfabetização matemática, que é um pensamento crítico sobre argumentos que usam a matemática para quebrar paradigmas no processo ensino-aprendizagem. Nos estudos observacionais, a alfabetização matemática depende do contexto de aprendizagem. Esse foco no contexto é o motivo pelo qual a matemática pode ser vista como um componente essencial de uma educação libertadora (Freire, 2019). E dado o papel da matemática como disciplina libertadora para entender fenômenos do cotidiano, a alfabetização matemática deve ser um componente essencial da educação para uma cidadania responsável e tomada de decisão mais eficaz.

O letramento estatístico se encontra em diferentes contextos sociais, basta abrir um jornal ou uma revista para encontrar diversos tipos de notícias acompanhadas de conceitos e gráficos estatísticos. Wallman (1993) afirmou que letramento estatístico é a capacidade de compreender e avaliar criticamente resultados estatísticos que permeiam diariamente nossas vidas, juntamente com a capacidade de apreciar as contribuições que o pensamento estatístico pode fazer para decisões públicas e privadas, profissionais e pessoais. Para ele, no nível mais alto da hierarquia do letramento estatístico, os estudantes teriam confiança para desafiar o que leem na mídia. Ressalta a tendência nos contextos da mídia para que as declarações sejam feitas sem base estatística apropriada, inadvertidamente ou às vezes propositadamente. Sendo assim, Gal (2002) problematizou a conceituação de letramento estatístico vinculado ao que se espera dos adultos participantes das sociedades complexas, propondo um sentido de letramento estatístico que se refere a dois componentes que se inter-relacionam: (a) a capacidade das pessoas de interpretar e avaliar criticamente informações estatísticas, argumentos relacionados a dados ou fenômenos estocásticos, que eles podem encontrar em diversos contextos, e quando relevante; e (b) a capacidade delas discutirem ou comunicarem as suas reações a essas informações estatísticas, tais como a sua compreensão do significado da informação, suas opiniões sobre as implicações desta informação, ou as suas preocupações quanto à aceitabilidade de determinadas conclusões.

Segundo Wallman (1993), letramento estatístico é a capacidade que um indivíduo tem para avaliar e chegar a uma compreensão crítica acerca de dados estatísticos que fazem parte de nosso cotidiano e reconhecer que a matemática pode contribuir para isso em todos os âmbitos. Dessa maneira, em nosso cotidiano sempre recebemos informações advindas, principalmente da mídia relacionadas à saúde, educação, inflação, moradia etc. Sendo assim, precisamos buscar meios que nos façam interpretar corretamente esses dados, e partir para a tomada de decisões. Então, a escola deve proporcionar aos alunos as ferramentas necessárias, pois o ensino de matemática assume papel importante na formação do cidadão, referente à compreensão de sua realidade por meio da discussão e da manipulação dessas informações e, até mesmo, capacitando-o para tomar decisões, permitindo, assim, que não se torne um refém da interpretação de dados (Kataoka, et al., 2011, p. 235).

No ensino da educação e aprendizagem da matemática, um outro tópico bastante pesquisado no ensino fundamental e médio, refere-se à aprendizagem de gráficos, tanto na construção, como na sua interpretação. Os gráficos são instrumentos importantes, pois ajudam na interpretação de dados nas mais diferentes áreas do conhecimento humano. Os gráficos modernos têm funções muito maior que o de substituir tabelas ou outras formas de comunicar informações. Na verdade, eles são instrumentos que ajudam a raciocinar sobre a informação quantitativa. De todos os métodos para analisar e comunicar informações, os gráficos bem desenhados são, geralmente, os mais simples e, ao mesmo tempo, os mais poderosos instrumentos de informação (Tufte, 1983). Segundo Pinker (1990), quando se ler um gráfico, aciona-se uma série de processos que estão ligados à capacidade cognitiva do leitor: o processo de reconhecimento, que reconhece um gráfico como pertencendo a um tipo particular; o processo de montagem da mensagem, que cria uma mensagem conceitual (informação disponível a ser extraída); o processo de interrogação, que recupera ou codifica uma nova informação baseada numa questão conceitual

expert em análises quanti-qualitativas de dados, e as empresas os contratavam para analisar seu desempenho geral e vendas. Com o rápido desenvolvimento da ciência da computação, armazenamento em nuvem e ferramentas analíticas, o campo da ciência da computação se fundiu com a estatística, dando origem à Data Science (Grus, 2016). expert em análises quanti-qualitativas de dados, e as empresas os contratavam para analisar seu desempenho geral e vendas. Com o rápido desenvolvimento da ciência da computação, armazenamento em nuvem e ferramentas analíticas, o campo da ciência da computação se fundiu com a estatística, dando origem à Data Science (Grus, 2016). 
(informação desejada) e o processo inferencial, que aplica as regras da inferência lógica e matemática para as entradas da mensagem conceitual. O sucesso dos gráficos reside na capacidade humana de reconhecer padrões (Shah \& Carpenter, 1995; Leinhardt et al., 1995). Diante da concepção dos gráficos, Curcio (1987) afirmou que a compreensão da informação em uma sociedade altamente tecnológica torna-se dependente da habilidade do leitor para, dentre outras coisas, compreender gráficos. Embora a leitura literal dos dados apresentados na forma gráfica seja um componente importante da leitura de gráficos, o máximo potencial de um gráfico é alcançado quando o leitor é capaz de interpretar e generalizar a forma dos dados apresentados. Consequentemente, os indivíduos que não conseguem interpretar corretamente os gráficos ou detectar incorreção nos mesmos, dependem da integridade e interpretação de outras pessoas.

De acordo com Nacarato e Lopes (2009, p.49), o letramento seria, pois, resultado da ação de ensinar a ler e a escrever: o estado ou a condição que adquire um grupo social ou um indivíduo como consequência de ter se apropriado da escrita. Deste modo, o ser letrado seria um resultado da ação de ler e a escrever, na qual, são adquirido um estado ou condição de uma consequência que se apropria a escrita de determinado contexto social e individual.

O vírus Sars Cov-2 (COVID-19) apareceu primeiramente na China e espalhou-se pelo mundo (Riyapan et al., 2021), chegando rapidamente no Brasil, causado, até à presente data, mais de 600 mil mortes. A pandemia do COVID-19 é a maior crise sanitária do Brasil. Assim que a pandemia do COVID-19 apareceu, os principais centros de epidemiologia do planeta, imediatamente procuraram realizar estudos que ajudassem a atenuar a proliferação da contaminação de pessoas. No Reino Unido, pesquisadores mostraram que, se não houvesse medidas de contenção sanitária, mais de 500 mil pessoas morreriam por COVID-19 (Griffiths, 2020). Essa estimativa foi realizada com base em estudos de modelos matemáticos específicos usados na epidemiologia. Os modelos matemáticos mostraram a importância de se adotar procedimentos sanitários, tais como o uso de máscaras, distanciamento social e isolamento social. Assim, a matemática se constituiu a medida não farmacológica mais importante para combater a proliferação da contaminação de pessoas com o COVID-19.

No Brasil, pesquisadores também mostraram a importância dos modelos matemáticos com a finalidade de entender a proliferação do COVID-19 na população (Reis, et al., 2020a; Reis, et al., 2020b). Esses estudos matemáticos serviram para alertar aos órgãos sanitários do Brasil, a necessidade de se adotar medidas de contenção do patógeno. Apesar dos alertas feitos pelos órgãos de Vigilância Sanitária/Epidemiológica, entretanto, decorrente de decisões políticas que resultaram em medidas sanitárias equivocadas por parte do Governo Federal, o Brasil amargou atualmente, a cifra de mais de 600 mil pessoas mortas pelo COVID-19. Essas mortes poderiam ter sido evitadas, se os procedimentos de alerta que foram dadas pelos pesquisadores do Reino Unido, tivessem sido aplicadas no Brasil. Tragicamente, o mesmo número de mortes previsto pelos modelos matemáticos ingleses, como citado por Griffiths (2020), é inferior à quantidade de mortes causadas pelo COVID-19, atualmente no Brasil.

No caso específico dos dados provenientes do número de pessoas contaminadas com o COVID-19 no Brasil, as funções matemáticas de crescimento podem ser facilmente utilizadas para acompanhar o comportamento da evolução da curva pandêmica. O estudo de funções matemáticas é um dos recursos de ensino que pode ser utilizado de maneira bastante eficiente em data science. Com isso, é possível realizar o ajuste dos dados e saber qual o comportamento de uma determinada curva.

Sendo assim, e dentro desse contexto, o objetivo do presente trabalho foi mostrar a importância das funções matemáticas de crescimento na análise de dados científicos no ensino médio, como foco no número de casos de pessoas contaminadas com o COVID-19 no Brasil. Para tanto, utilizou-se de uma pesquisa quantitativa exploratória de dados na Plataforma do Ministério da Saúde do Brasil, especificamente, no Painel de casos de doença pelo coronavírus 2019. 


\section{Metodologia}

\subsection{Tipo de pesquisa}

O presente estudo baseou-se em uma pesquisa de estratégia quantitativa, de caráter exploratória, por meio de uma pesquisa de dados no site do Ministério da Saúde do Brasil (Brasil, 2021b), especificamente, na obtenção dos números de casos de pessoas contaminadas e mortas pelo COVID-19. A escolha desse tipo de pesquisa baseou-se nas raízes no pensamento positivista lógico, enfatizando assim o raciocínio dedutivo, as regras da lógica e os atributos mensuráveis da experiência humana.

Inicialmente, foram realizadas coletas de dados no mês de junho de 2021. Em seguida, os números de casos acumulados de pessoas contaminadas e mortas pelo novo coronavírus (COVID-19) foram transferidos para uma Planilha do aplicativo Excel $^{\circledR}$, onde foram realizadas as análises dos dados com os ajustes das curvas para as funções matemáticas de crescimento exponencial natural, potência e polinomial.

\subsubsection{Dados do coronavírus no Brasil}

Em dezembro de 2019, um surto local de pneumonia de etiologia desconhecida foi detectado na cidade de Wuhan, província de Hubei, na China (WHO, 2020a). Essa nova doença foi batizada de novo coronavírus (COVID-19). O surto se espalhou rapidamente pela China e por 18 países com 83 casos confirmados até o final de janeiro de 2020 (WHO, 2020b). A Organização Mundial da Saúde (WHO, 2020c) declarou o surto de COVID-19 como uma pandemia em 11 de março de 2020. Evidências científicas mostraram que o COVID-19 era facilmente transmitido de humano para humano (WHO, 2020b). Entretanto, em 17 de abril de 2020, houve 2.074 .529 casos confirmados em mais de 200 países e territórios, com 139.378 casos de mortes confirmadas. Segundo Cavalcante et al. (2020), até o fim da Semana Epidemiológica (SE) 20, no Brasil havia 233.142 casos, 15.633 óbitos confirmados e 3.240 (58,2\%) dos municípios apresentavam pelo menos um caso. O Brasil estava em uma fase anterior da pandemia quando comparado aos demais países, exceto Rússia e Turquia, em casos acumulados, e Canadá, em óbitos acumulados. As maiores taxas foram encontradas em Unidades da Federação da Região Norte, com o Amazonas apresentando as maiores taxas de incidência (4.474,6/1 milhão) e mortalidade (331,8/1 milhão) (Cavalcante et al., 2020). Esses autores concluíram que o Brasil estava entre os países com maiores números de casos e óbitos confirmados, exibindo notáveis diferenças regionais. Desde o início da pandemia do COVID-19 no Brasil até a presente data, o número de pessoas contaminadas tem aumentado sempre (Figura 1) e causado muitas mortes (Figura 2). 
Figura 1. Casos acumulados de pessoas contaminadas pelo COVID-19 no Brasil.

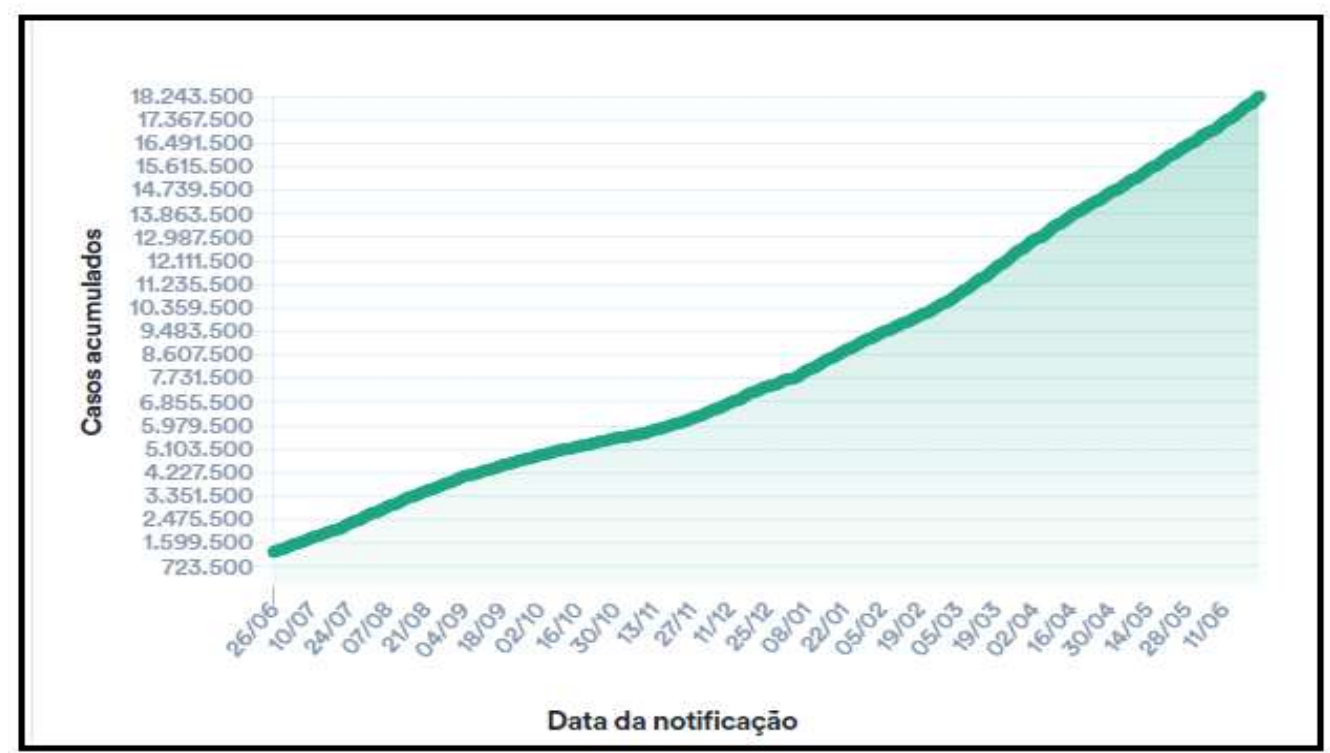

Fonte: Ministério da Saúde (Brasil, 2021b).

Figura 2. Casos de óbitos acumulados causados pelo COVID-19 no Brasil.

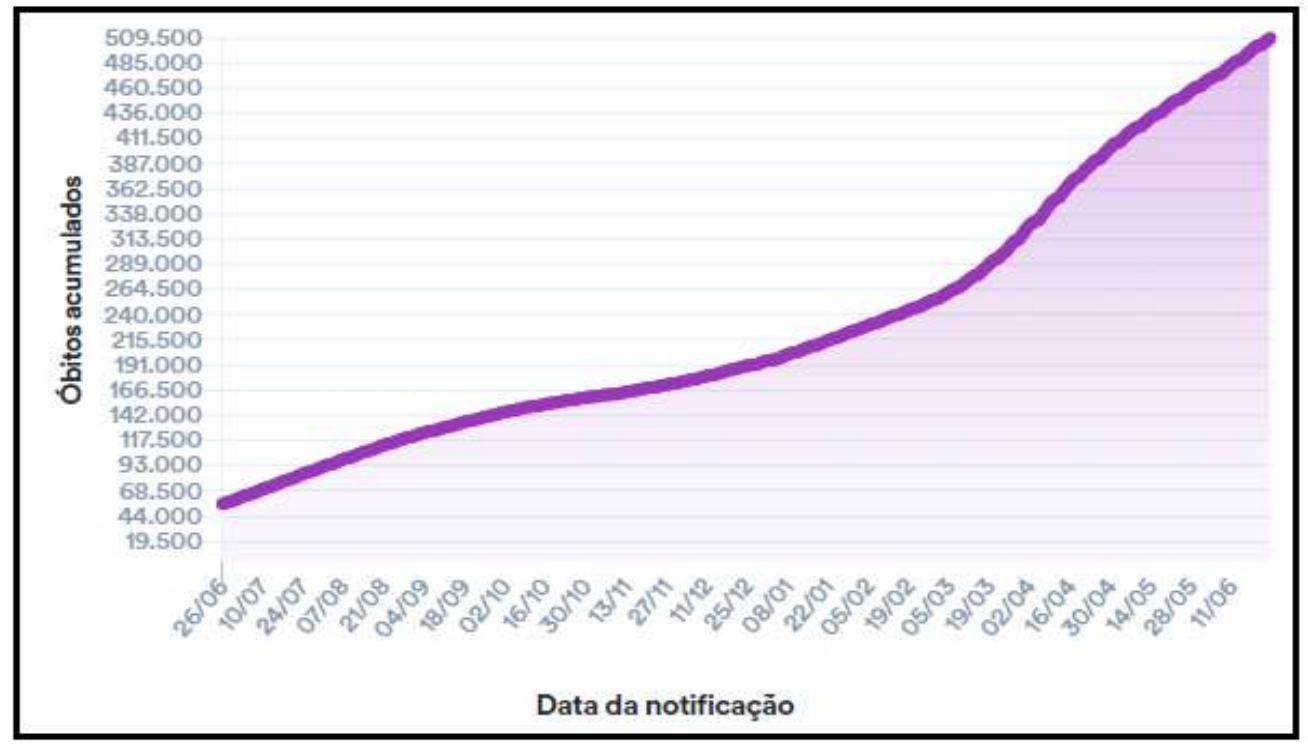

Fonte: Ministério da Saúde (Brasil, 2021b).

Os recursos matemáticos devem ser abordados na escola de tal maneira que os alunos se sintam motivados a usá-los para compreender o nosso mundo. A matemática ensinada de forma descontextualizada nada acrescenta à vida do educando. Apesar de estarmos vivendo na pior crise sanitária da história do Brasil, a pandemia do COVID-19 tem nos ensinado muitas lições, sendo uma delas a falta de compreensão de estudos epidemiológicos relacionados ao ensino da matemática. Isso é de vital importância, pois, o conhecimento de como uma pandemia se propaga, nos ajudarão a tomar as devidas medidas de combate e segurança sanitária, tais como o isolamento social, distanciamento social e o uso de máscaras, por exemplos. Assim, a matemática forma um conjunto de recursos não farmacológicos que devem ser introduzidos no processo ensinoaprendizagem na comunidade estudantil, com a finalidade de compreender a disseminação de um elemento patógeno numa dada população, como tem sido o caso da pandemia do COVID-19 no Brasil. 
Os números de casos acumulados de pessoas contaminadas e mortas pelo novo coronavírus no Brasil, podem ser utilizados em estudos matemáticos de funções e ciência de dados, com a finalidade de mostrar aos estudantes do ensino médio, a propagação da doença no país e quais são as medidas sanitárias que devem ser tomadas.

\subsubsection{Funções matemáticas no Ensino Médio}

As funções são usadas em todos os ramos da matemática, principalmente, em matemática aplicada. Função é um conceito unificador em toda a matemática. Relações entre fenômenos da vida cotidiana, como a relação entre a velocidade de um carro e a distância percorrida são funções. Nesse caso, sem entrar em discussão de detalhes físicos sobre os tipos de velocidades, mas, apenas por questão de conceitos básicos e didáticos de velocidade, a velocidade (v) é a razão entre a distância percorrida (d) e o tempo gasto (t) em percorrê-la. Portanto, $d$ = v.t, que é uma relação funcional que envolve três grandezas fundamentais da física. Sendo v constante, teremos uma função linear, onde "d" é a variável dependente e "t" a variável independente.

O conceito de função tem uma parte importante no currículo escolar de matemática no ensino médio. Entretanto, o tema tem sido pouco explorado como elemento presente no cotidiano dos estudantes.

O conceito de função passou por uma evolução interessante. Os desenvolvimentos na matemática mudaram o conceito de função de uma curva descrita por um movimento (século 17) para uma expressão analítica composta de variáveis e constantes que representam a relação entre duas ou mais variáveis (século 18). Nos séculos 19 e 20, novas descobertas e nova ênfase no rigor levaram ao conceito moderno de uma função como uma correspondência univalente entre dois conjuntos (Denbel, 2015).

À medida que a disciplina da matemática cresceu, a função tornou-se um dos conceitos matemáticos mais importantes e fundamentais como forma de organizar e caracterizar as relações matemáticas. O desenvolvimento do conceito de função na matemática influenciou a maneira como a função entrou e foi apresentada na matemática escolar. O conceito de função apareceu no currículo de matemática secundária no início do século 20, ampliado pela criação da Comissão Internacional de Instrução Matemática (ICMI) em 1908. O termo "função" era usado então de forma semelhante à definição de Euler do século XVIII. Função, no sentido moderno, foi introduzida no currículo escolar em muitos países durante a "nova reforma matemática" dos anos 1950-1960, muitas vezes usando o conceito de função como um tema organizador para o currículo de matemática secundária (Denbel, 2015).

A função, em matemática, é uma expressão, regra ou lei que define uma relação entre uma variável (a variável independente) e outra variável (a variável dependente). As funções são onipresentes na matemática e são essenciais para a formulação de relações físicas nas ciências. A definição moderna de função foi dada pela primeira vez em 1837 pelo matemático alemão Peter Dirichlet: "Se uma variável “ $y$ ” está relacionada a uma variável “ $x$ ”, sempre que um valor numérico é atribuído a " $x$ ", há uma regra segundo a qual um valor único de " $y$ ” é determinado, e então " $y$ ” é dito ser uma função da variável independente " $x$ " (Britannica, 2021). Essa relação é comumente simbolizada como $y=f(x)$. Além de $f(x)$, outros símbolos abreviados como $g(x)$ e $P(x)$ são frequentemente usados para representar funções da variável independente " $x$ ", especialmente quando a natureza da função é desconhecida ou não especificada.

Hoje, o conceito moderno de função aparece em muitos currículos escolares de matemática. Uma expectativa comum é que, ao final do ensino médio, os alunos conheçam o conceito de função em geral e estejam familiarizados com tipos específicos de funções, incluindo a linear, quadrática, polinomial, recíproca, potência, degrau, exponencial, logarítmica, trigonométrica e funções em diferentes representações. Entretanto, o que se observa na prática, é que os alunos do ensino médio têm dificuldades em aprender o conceito de função. E, embora o temo "função matemática" seja frequentemente 
definida em livros didáticos em um sentido moderno, os alunos tendem a manter uma imagem restrita do que seja "função", semelhante à do século 18, quando a função era uma variável dependente ou apenas uma expressão analítica (Denbel, 2015).

Além dos problemas decorrentes das imagens restritas dos alunos ao alcance da noção de função, há evidências de que as diferentes representações de funções muitas vezes permanecem e são tratadas isoladamente, sem as conexões que as tornam representações de um conceito central comum. Além disso, parece haver uma incerteza crescente entre designers de currículo, autores de livros didáticos, professores e outros sobre os propósitos e objetivos do estudo de funções, em particular no que diz respeito à ênfase relativa em objetivos intramatemáticos e objetivos relacionados a aplicações e modelagem. Tudo isso dá origem ao que se pode chamar de "crise de identidade" no ensino e na aprendizagem de funções na escola (Denbel, 2015).

Alguns países ou estados têm um currículo oficial, enquanto outros não. No entanto, mesmo em países que têm um currículo oficial de matemática nacional, os objetivos do currículo podem ser diferentes para diferentes grupos de alunos (Denbel, 2015). Cada currículo deve possuir metas específicas para o estudo de funções matemáticas. Existem vários propósitos diferentes para incluir funções no currículo.

Denbel (2015) apresentou quatro propósitos específicos para que haja sucesso no aprendizado de funções matemáticas no ensino médio: (1) incluir a função como um tópico matemático que é percebido como uma parte intrínseca da matemática por si só. Para alguns alunos, isso pode ocorrer porque as funções provavelmente ocorrerão em seus estudos posteriores; (2) deve-se apresentar o conceito de função como um conceito unificador em todo o currículo matemático. Por exemplo, as transformações geométricas do plano podem ser percebidas e investigadas como funções. O mesmo é verdadeiro para operações aritméticas, alguns conjuntos de solução para equações, fórmulas usadas para encontrar (comprimento, área e volume), probabilidades, funções de regressão, definição recursiva de objetos etc; (3) usar funções como um veículo para esclarecer o pensamento e raciocínio matemático, como uma ferramenta para comprovar afirmações e coisas do gênero; e (4) usar funções para fornecer um meio para fins extramatemáticos, em particular para representar, descrever e lidar com (ou seja, para modelar) fenômenos, situações ou problemas fora da própria matemática. Em alguns países e estados, esse propósito é um dos principais impulsionadores do currículo, provocando a crise de identidade mencionada acima.

Os propósitos apresentados acima são essenciais para aprimorar o uso das funções matemáticas no processo ensinoaprendizagem na escola. Logicamente, devem ser esclarecidos quais propósitos precisam ser aplicados em um determinado programa ou contexto de ensino, já que eles vão moldar e influenciar de forma crucial a forma com que está acontecendo o ensino e a aprendizagem. Em particular, é importante considerar se as necessidades de diferentes grupos de alunos devem dar origem à busca de objetivos diferentes para esses grupos. Ao olhar para o estado atual e o desenvolvimento dos currículos do ensino médio em todo o mundo, parece que uma dicotomia está emergindo entre a adoção e a busca de um propósito de modelagem, por um lado, e um propósito intrinsecamente matemático, por outro lado, para o estudo das funções. Isso é muito bom para o ensino da matemática, entretanto, esforços devem ser feitos para encontrar um equilíbrio adequado entre os dois tipos de propósitos. Os Parâmetros Curriculares Nacionais (PCN’s) (Brasil, 1999, p. 111) afirmaram que:

O conhecimento matemático é necessário em uma grande variedade de situações, como apoio a outras áreas do conhecimento, sendo também instrumento para lidar com situações cotidianas, ou como forma de desenvolver habilidades de pensamento.

No contexto referendado nos Parâmetros Curriculares Nacionais (PCN's) (Brasil, 1999, p. 210), em relação ao ensino da matemática, observar-se que:

O Ensino Médio precisa desenvolver o saber matemático científico e tecnológico como condição de cidadania e não como prerrogativa de especialistas. 
Dadas as atribuições contidas nos PCN's (Brasil, 1999), ao concluir o ensino médio, os alunos devem saber usar a matemática como uma ferramenta capaz de resolver problemas do cotidiano e entender os aspectos intra e extramatemáticos. Tais aspectos são importantes para compreender a matemática e sua aplicação nas mais diversas áreas do conhecimento, além de ser parte fundamental para o desenvolvimento científico e tecnológico de uma nação. Certamente, no bojo do ensinoaprendizagem, a ciência de dados deve ser parte profícua dentro dos PCN's do Brasil, mesmo que ali esteja de forma fíctícia no ensino de funções matemáticas.

As escolas de ensino médio no Brasil devem adaptar os estudos de funções matemáticas com a ciência de dados. Certamente, isso ajudará os alunos a descobrirem novos horizontes de aplicação da matemática para resolver problemas reais em qualquer área do conhecimento humano, especialmente, em estudos epidemiológicos que lidam constantemente com modelos matemáticos padrões. Nesse caso, os estudos das funções matemáticas são importantes para se estimar o processo de crescimento do número de pessoas contaminadas, como também o número de óbitos. Porém, é preciso quebrar paradigmas no ensino médio das escolas brasileiras. Para que isso aconteça, é necessário que durante o processo ensino-aprendizagem, os professores realizem atividades que agucem a criatividade matemática dos seus alunos. Sobre a importância de se estudar funções no ensino médio e analisar o potencial didático-pedagógico de atividades realizadas em sala de aula, Meneghetti e Redling (2012) chegaram aos seguintes resultados:

Verificamos que essa abordagem se mostrou como uma alternativa ao favorecimento de uma aprendizagem mais significativa para o ensino de funções, visto que permitiu o estabelecimento de uma relação entre o que os alunos já sabiam e o que lhes estava sendo apresentado, possibilitando o surgimento de diversas soluções a partir de seus conhecimentos prévios.

Assim, de acordo com Meneghetti e Redling (2012), o ensino de funções no ensino médio deve ir além do puro algebrismo matemático, mas alcançar de forma equânime todos os alunos para o aprendizado na vida real.

Funções matemáticas de crescimento são ferramentas indispensáveis em estudos epidemiológicos. Ultimamente, em decorrência do surgimento do novo coronavírus, a epidemiologia tem estado em evidência no meio acadêmico e científico. Apesar de ser um tema complexo e extremamente debatido nas áreas de saúde e na biomatemática, a epidemiologia matemática pode ser estudada no ensino médio através de conceitos básicos. As funções matemáticas como a função potência, exponencial e polinomial podem ser implementadas no programa de ensino médio para se estudar eventos pandêmicos, como o COVID-19. Bush et al. (2015) realizaram um trabalho interessante sobre modelagem de função exponencial no ensino médio, com a finalidade de estudar eventos pandêmicos. Semelhantemente, é possível utilizar as funções potência, exponencial e polinomial para se estudar o comportamento do crescimento do número de casos do COVID-19 no Brasil.

\subsubsection{Função exponencial natural}

A função exponencial é uma função $f: \mathbb{R} \rightarrow \mathbb{R}_{+}^{*}$, ou seja, seu domínio é o conjunto dos números reais, e seu contradomínio é o conjunto dos números reais positivos diferentes de 0 . As funções exponenciais têm a seguinte lei de formação $f(x)=k b^{a x}$, onde "k", "a" e "b" são constantes > 0 e $b \neq 1$. Considerando "k" e "a" igual a 1 na lei de formação $\mathrm{f}(\mathrm{x})=\mathrm{kb}^{\mathrm{ax}}$, e b > 1, temos $\mathrm{f}(\mathrm{x})=\mathrm{b}^{\mathrm{x}}$. Assim, como em qualquer expressão exponencial, "b" é chamado de base e $x$ é chamado de expoente. Assim, quanto mais o valor de "x" aumentar, maior será o valor de $f(x)$. Nesse caso, tem-se uma função exponencial crescente (Figura 3). Quando o valor de "b" for maior do que zero e menor do que 1, ou seja, $0<b<1_{x}$ a função exponencial será decrescente (Figura 4). Nesse caso, quanto maior o valor de " $\mathrm{x}$ ", menor será o valor de f(x). 
Figura 3. Gráfico da função exponencial crescente.

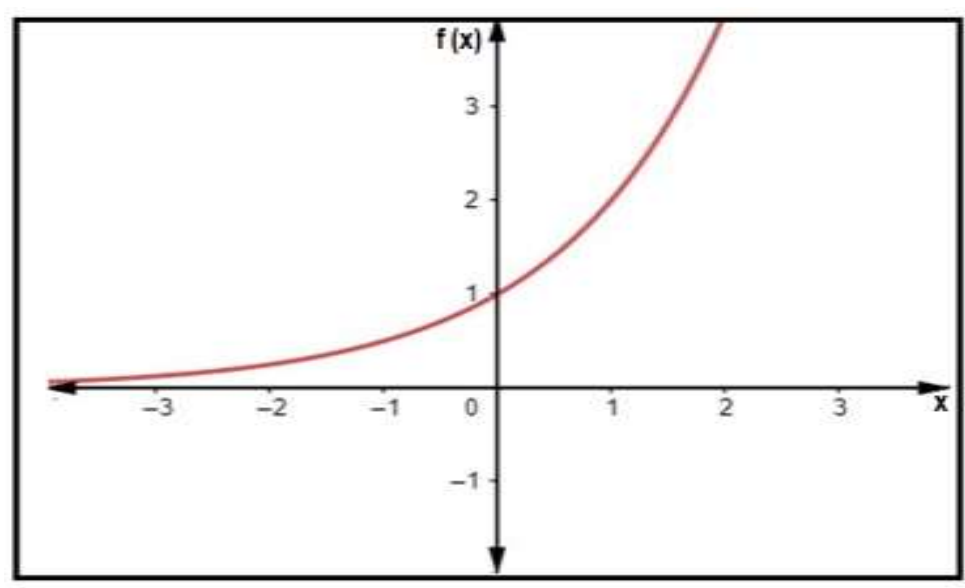

Fonte: Autores (2021).

Figura 4. Gráfico da função exponencial decrescente.

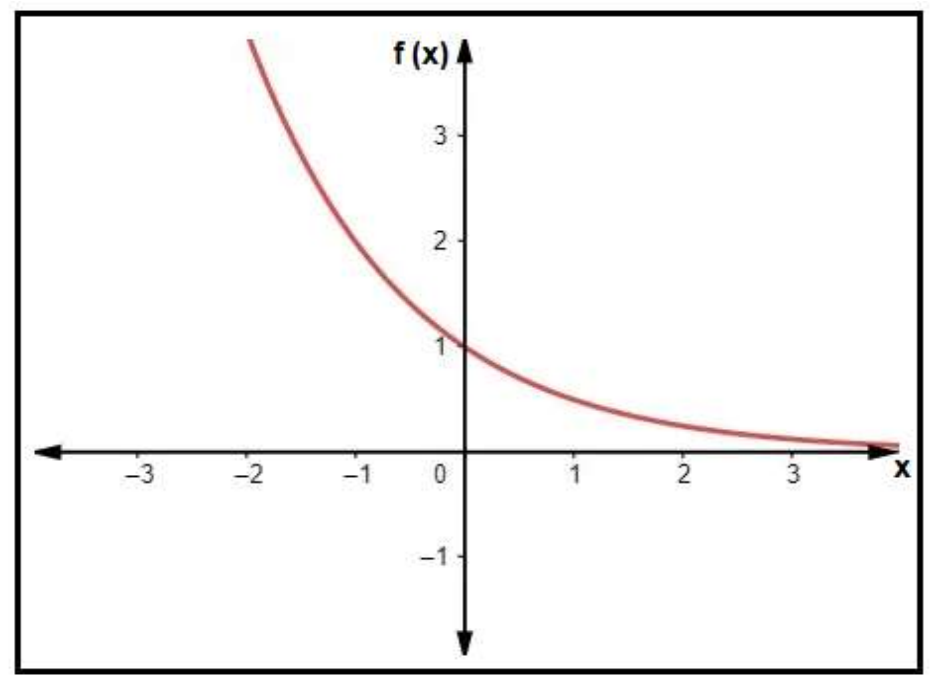

Fonte: Autores (2021).

Um fato interessante que ocorre na lei de formação $\mathrm{f}(\mathrm{x})=\mathrm{kb} \mathrm{b}^{\mathrm{ax}}$, diz respeito à mudança de base quando $\mathrm{b}=\mathrm{e}$, onde “e” é um número irracional denominado de constante de Euler. Sendo assim, temos $\mathrm{f}(\mathrm{x})=\mathrm{ke} \mathrm{ex}^{\mathrm{ax}}$ Para " $\mathrm{k}$ " e "a" igual a 1 , temos $\mathrm{f}(\mathrm{x})=\mathrm{e}^{\mathrm{x}}$. A função $\mathrm{f}(\mathrm{x})=\mathrm{e}^{\mathrm{x}}$ é a única função em que a inclinação de uma tangente à curva em qualquer ponto é igual à altura da curva naquele ponto (Figura 5). 
Figura 5. Gráfico da função $f(x)=e^{x}$.

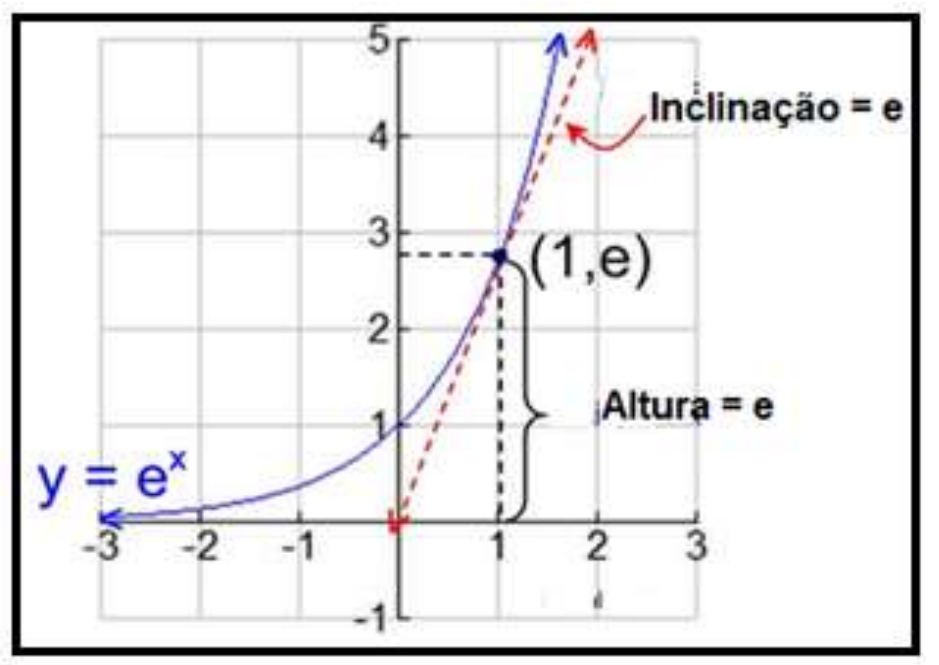

Fonte: Autores (2021).

\subsubsection{Função potência}

Qualquer expressão dada pela lei de formação $f(x)=k x^{n}$, onde "k" e "n" são constantes $>0$, sendo "n" fixo, é chamada de função potência. A forma geral do gráfico de $\mathrm{f}(\mathrm{x})=\mathrm{kx}^{\mathrm{n}}$ depende de " $\mathrm{n}$ " ser par ou ímpar. Ao representar graficamente as funções de potência, devemos ter em mente as seguintes propriedades importantes: sua simetria e comportamento final. Ao identificar se uma função é uma função de potência, devemos nos certificar de que a expressão é um único termo, "k" é uma constante e "n" é um número real. Os gráficos das funções de potência dependerão sempre do valor de "k" e "n". Ao encontrar a expressão para uma função de potência, devemos utilizar sempre a forma geral, $\mathrm{f}(\mathrm{x})=\mathrm{kx}$.

\subsubsection{Função polinomial}

Toda função $f: \mathbb{R} \rightarrow \mathbb{R}$ é denominada de função polinomial quando a sua lei de formação é um polinômio: $f(x)=a_{n} x^{n}+a_{n-1} x^{n-1}+a_{n-2} x^{n-2}+\cdots+a_{2} x^{2}+a_{1} x+a_{0}$. Onde: "x" é a variável, "n" é um número natural e $a_{n}, a_{n-1}, a_{n-}$ $2, \ldots, \mathrm{a}_{2}, \mathrm{a}_{1}$ e $\mathrm{a}_{0}$ são coeficientes reais que acompanham a variável do polinômio. Assim sendo, uma função polinomial é uma função que envolve apenas potências inteiras não negativas ou apenas expoentes inteiros positivos de uma variável. Uma função polinomial, em geral, também é definida como uma expressão polinomial, definida por seu grau. O grau de qualquer polinômio é a maior potência presente nele. Muitas funções comuns são funções polinomiais.

\subsubsection{Simulador pandêmico}

Após os ajustes dos dados importados do Ministério da Saúde às funções matemáticas de crescimento, a necessidade de isolamento e distanciamento social foram ilustradas usando o aplicativo Construct 2. Assim, enquanto as funções matemáticas mostraram o rápido crescimento do número de casos do COVID-19, o aplicativo computacional Construct 2 ilustrou a importância de se adotar medidas sanitárias rígidas por parte das autoridades em saúde pública, com a finalidade de evitar o aumento desordenado do nível de contaminação com o patógeno.

A interação entre a matemática e a computação é fundamental no processo ensino-aprendizagem. Para melhorar a alfabetização matemática, a utilização de aplicativos computacionais específicos, na análise e interpretação de dados, constituise ferramenta importante como elemento motivador de aulas práticas. Programas de computadores, principalmente, os gratuitos, são extremamente benéficos para os alunos, pois com eles, os estudantes podem realizar muitas tarefas tais como: converter dados brutos em informações significativas, executar cálculos mais rapidamente, visualização de dados, 
planejamento financeiro, ajustes de curvas etc. Os alunos podem se tornar bons e proficientes em qualquer disciplina da escola ou faculdade usando os aplicativos computacionais. Eles são realmente importantes em nosso sistema educacional, pois aprimora a criatividade do gerenciamento de dados na mente dos alunos.

Os softwares matemáticos são recursos didáticos que devem ser utilizados amplamente dentro do processo ensinoaprendizagem. Existem várias razões pelas quais eles devem ser utilizados em sala de aula. Destacaremos aqui os principais: (a) os alunos podem fazer e aprender a maneira mais rápida de realizar cálculos com precisão; (b) cria fortes habilidades e pensamento analítico; (c) os alunos podem aprender como os cálculos são realizados; (d) os alunos podem aprender como os dados são visualizados. A aprendizagem da matemática usando softwares específicos é importante na execução de tarefas essenciais que contribuirão para a formação geral do educando, ajudando-o, para que no futuro, ele saiba lidar com grande quantidade de dados e informações com facilidade e precisão. Tudo isso mostra o papel que os softwares matemáticos possuem no processo da alfabetização matemática.

Os jogos podem ser usados como uma ferramenta de suporte para complementar os métodos tradicionais de ensino, melhorando a experiência de aprendizagem dos alunos, ao mesmo tempo que ensina outras habilidades, como seguir regras, adaptação, resolução de problemas, interação, habilidades de pensamento crítico, criatividade, trabalho em equipe e desenvolve o bom espírito esportivo (Zirawaga et al., 2017). A aprendizagem não deve ser entediante, baseada na memorização mecânica, onde os alunos aprendem conceitos por meio de repetição. Os professores como agentes motivadores do processo ensinoaprendizagem, podem proporcionar o uso da tecnologia para ajudar a melhorar o desempenho dos alunos.

$\mathrm{O}$ uso de ferramentas atuais e emergentes na educação está se tornando um tópico de grande interesse entre os professores e instituições educacionais, principalmente, aquelas que utilizam jogos como elementos de contextualização no ensino-aprendizagem. Quando corretamente utilizados, os jogos são ferramentas motivadoras na aprendizagem. Lembrando sempre que, uma educação voltada para o aprendizado consciente tem como finalidade aumentar a motivação e o envolvimento dos alunos, visando aprimorar suas habilidades de interação com o mundo real.

Toda e qualquer tecnologia educacional que seja desenvolvida com a finalidade de melhorar a aprendizagem, deve sempre estar alinhada com o currículo, para que seja eficaz. Não se pode utilizar um recurso didático aleatoriamente em sala de aula, mesmo que ele possua expressivo avanço tecnológico. Todo e qualquer recurso tecnológico com fins de aplicação no processo ensino-aprendizagem, deve ter significado para a vida real do aluno, sendo elemento motivador na sua formação geral, ajudando-o a compreender e resolver problemas do dia a dia.

No contexto da utilização de jogos na educação, os jogos eletrônicos é uma boa alternativa com elemento instigante e motivador para a aprendizagem do alunado. Nos últimos anos, os jogos eletrônicos têm assumido um lugar importante na vida de crianças e adolescentes. As crianças adquirem a alfabetização digital informalmente, por meio de brincadeiras, e nem as escolas nem outras instituições educacionais levam suficientemente em consideração esse importante aspecto. Dentro do processo ensino-aprendizagem, os jogos eletrônicos podem combinar os recursos mais poderosos do design multimídia interativo com os princípios mais eficazes de aprendizagem mediada pela tecnologia. Um exame da evolução do design dos videogames é uma boa forma de analisar as principais contribuições e características dos ambientes de aprendizagem baseados em jogos. Entretanto, a temática carece de maiores discussões (Gros, 2007).

Usar a criação de jogos como uma ferramenta para a educação é uma das maneiras mais envolventes e empolgantes para os alunos aprenderem uma ampla gama de habilidades. Desde aprender os princípios da programação até trabalhar em equipe, fazer protótipos de ideias, publicar, fazer marketing e muito mais. Da educação primária à educação de adultos e em todas as áreas intermediárias, o Construct desenvolvido pela empresa Scirra Ltda é uma ferramenta perfeita para ser utilizada no processo ensino-aprendizagem. Construct é um programa utilizado para criar jogos de computador em HTML5, sem que haja qualquer experiência em programação, utilizando para tanto, um intuitivo, "drag and drop" ambiente de desenvolvimento. 
A maioria das ferramentas dos programas pode ser usada a partir da interface gráfica sem ter que escrever uma única linha de código.

Decorrente de sua versatilidade, o Construct pode ser utilizado em diversas atividades educacionais. A abordagem única baseada em blocos do Construct é uma maneira simples e emocionante de começar a projetar jogos educativos. Não há necessidade de aprender a sintaxe de linguagens de programação complicadas. Na presente pesquisa, ele foi utilizado para simular o número de pessoas contaminadas num evento pandêmico. Para tanto, utilizou-se o Construct 2 da Scirra para construir um simulador pandêmico com a finalidade de mostrar a proliferação de um agente patógeno numa dada população, apresentando a necessidade do isolamento social. O aplicativo desenvolvido foi utilizado para mostrar através da simulação computacional, como ocorre o crescimento do número de pessoas contaminadas com o COVID-19, e analisar também, a importância de se adotar medidas não farmacológicas para tentar atenuar a quantidade de mortes.

$\mathrm{Na}$ construção do aplicativo como recurso didático, primeiramente, considerou-se hipoteticamente, quatro (04) continentes que interagem entre si através do deslocamento de aviões que decolam dos seus respectivos aeroportos (Figura 6). No canto esquerdo do aplicativo existem as seguintes grandezas que foram simuladas: (1) o tempo; (2) número de pessoas saudáveis; (3) número de pessoas doentes; e (4) número de pessoas mortas. Nesse caso, cada bolinha branca que se movimenta aleatoriamente representa o número de pessoas saudáveis. Não havendo a ação de um agente patógeno, todas as bolinhas ficam brancas, indicando que não existem pessoas contaminadas. Os aviões de cor branca indicam que a população a bordo não foi contaminada. Quando uma bolinha fica vermelha, considera-se que houve uma contaminação (Figura 7).

Figura 6. Aplicativo desenvolvido com o Construct 2 da Scirra.

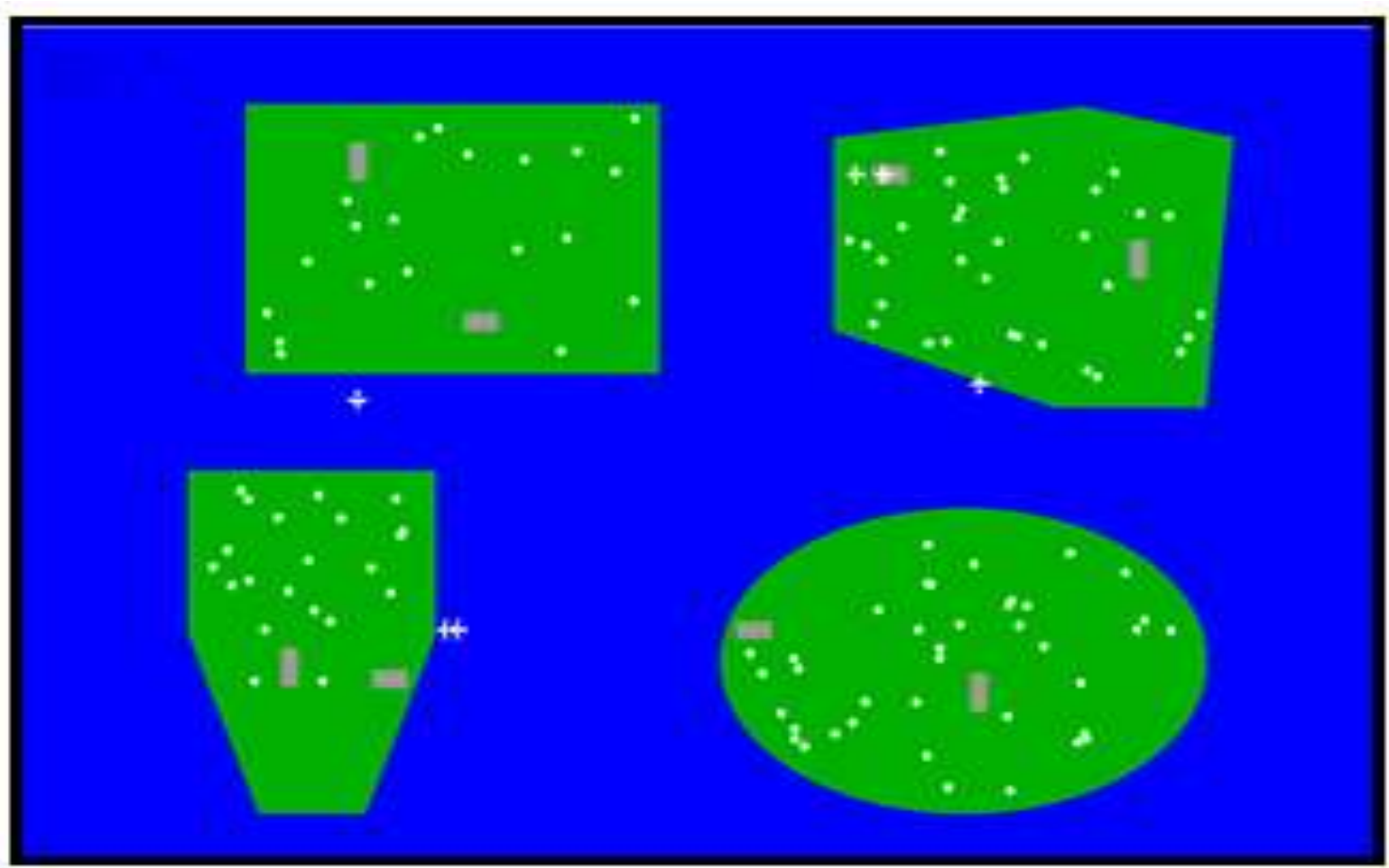

Fonte: Autores (2021). 
Figura 7. A bolinha vermelha indica o início da contaminação.

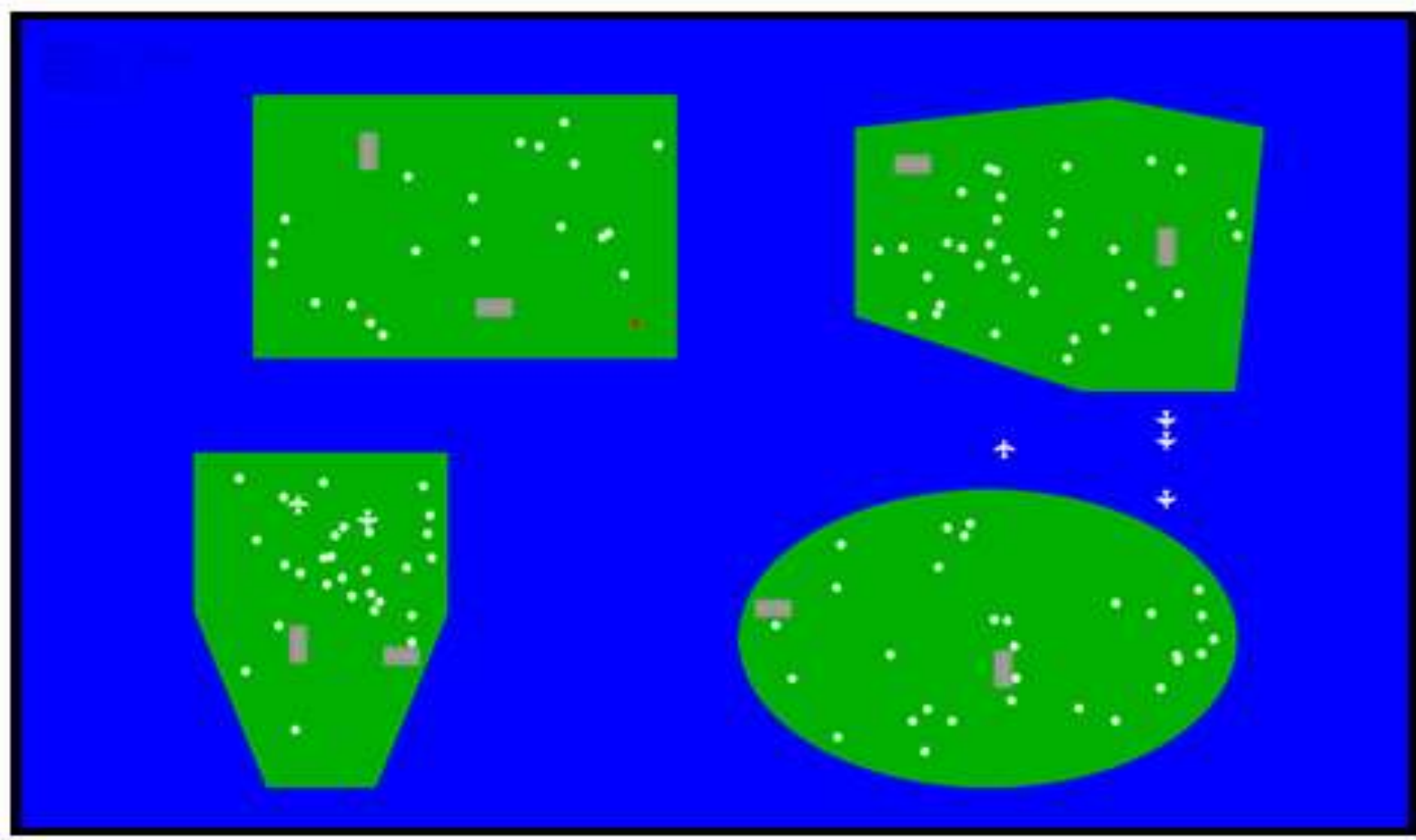

Fonte: Autores (2021).

Quando uma bolinha vermelha atinge uma bolinha branca, e assim, sucessivamente, pode-se considerar que o número de pessoas contaminadas aumenta consideravelmente com o passar do tempo (Figura 8).

Figura 8. Simulação do número de pessoas contaminadas (bolinha vermelha).

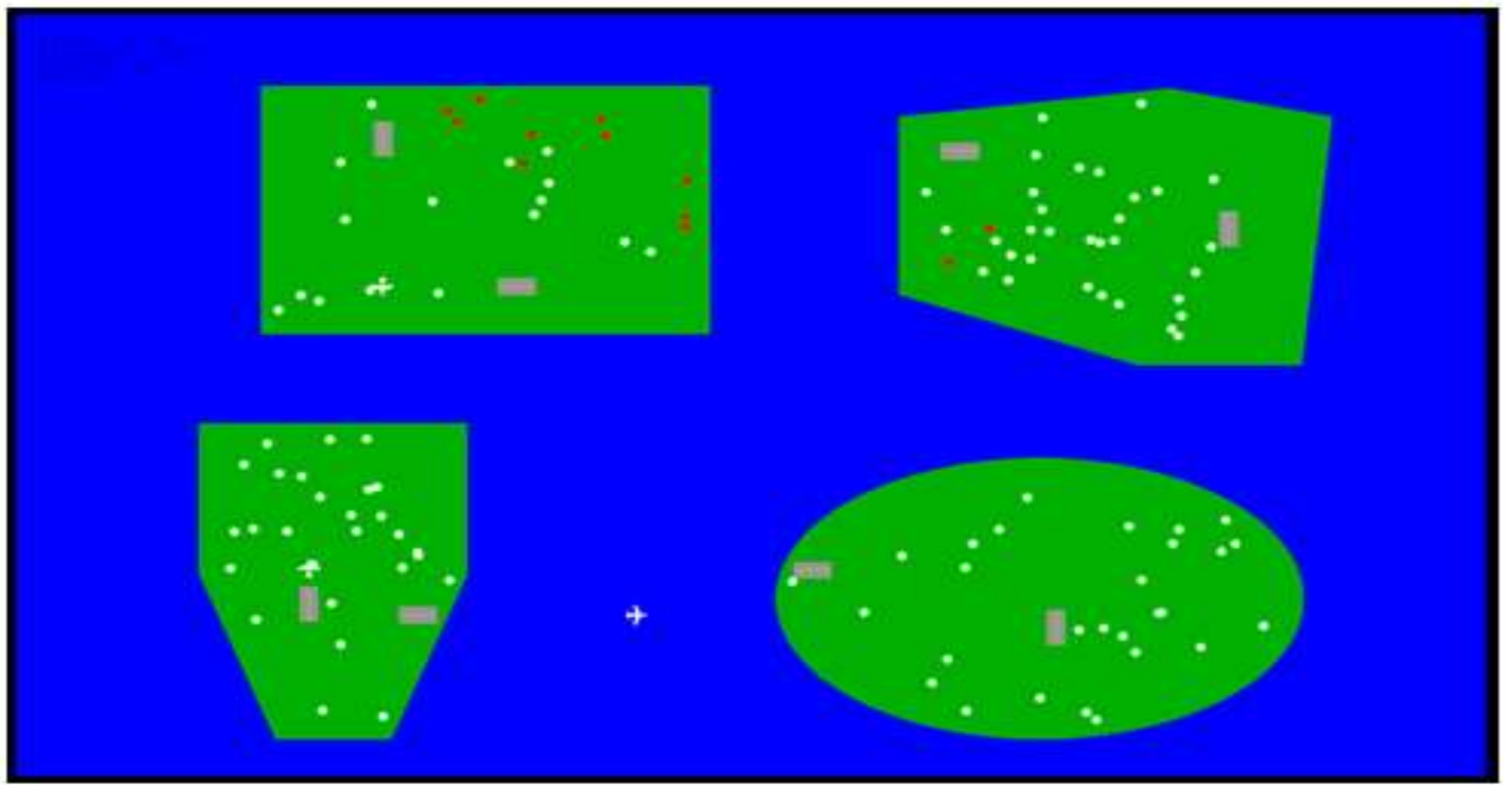

Fonte: Autores (2021).

Semelhantemente, quando uma bolinha vermelha atinge um aeroporto, o avião fica vermelho, simbolizando que o patógeno pode ser transferido de um continente a outro. $\mathrm{O}$ aparecimento de uma bolinha preta significa a ocorrência de morte na população (Figura 9). Caso, não haja nenhuma medida de restrição, o número de pessoas contaminadas aumenta significativamente (Figura 10). 
Figura 9. Simulação do número de contaminação e morte (bolinha vermelha e preta).

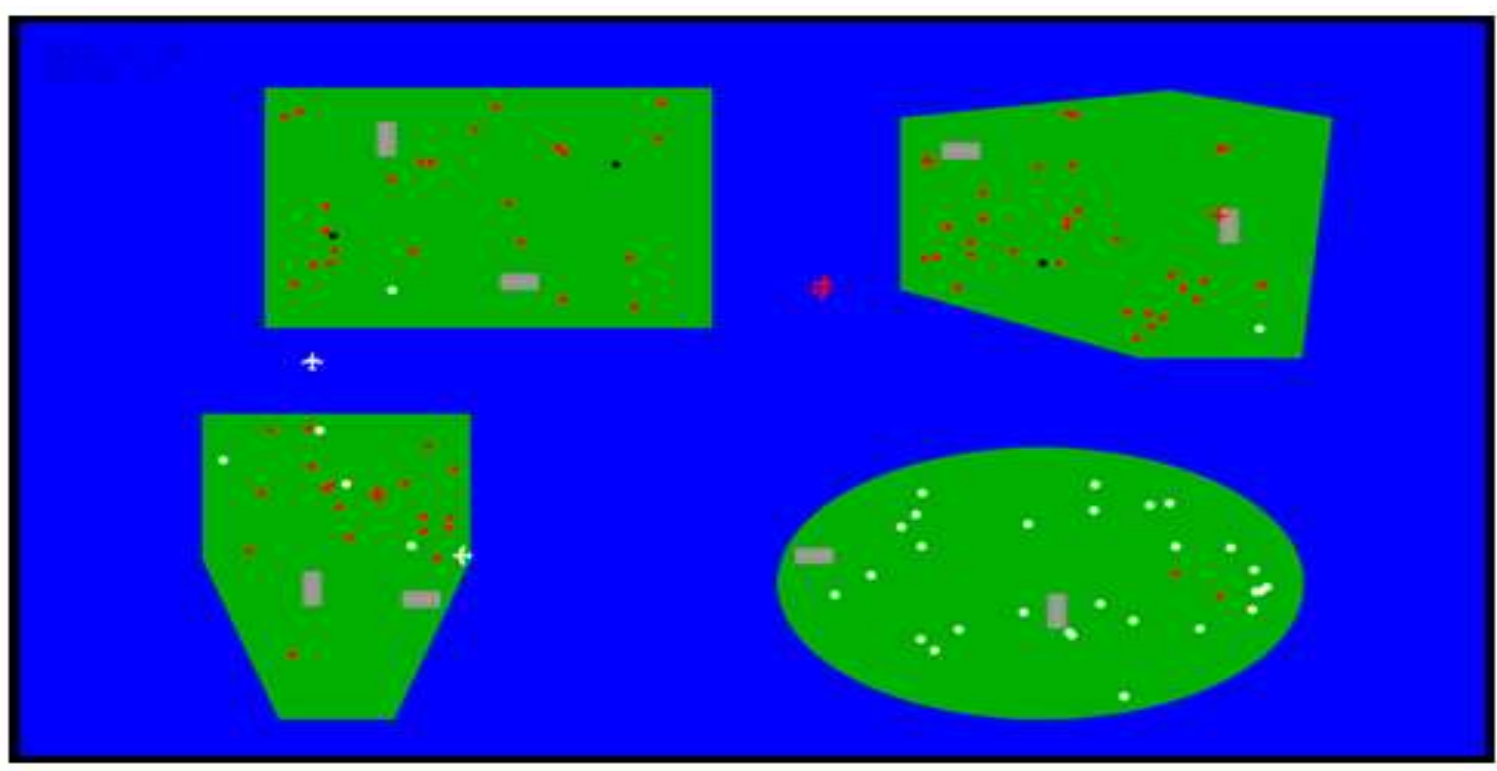

Fonte: Autores (2021).

Figura 10. Simulação da propagação da pandemia sem medidas de restrição.

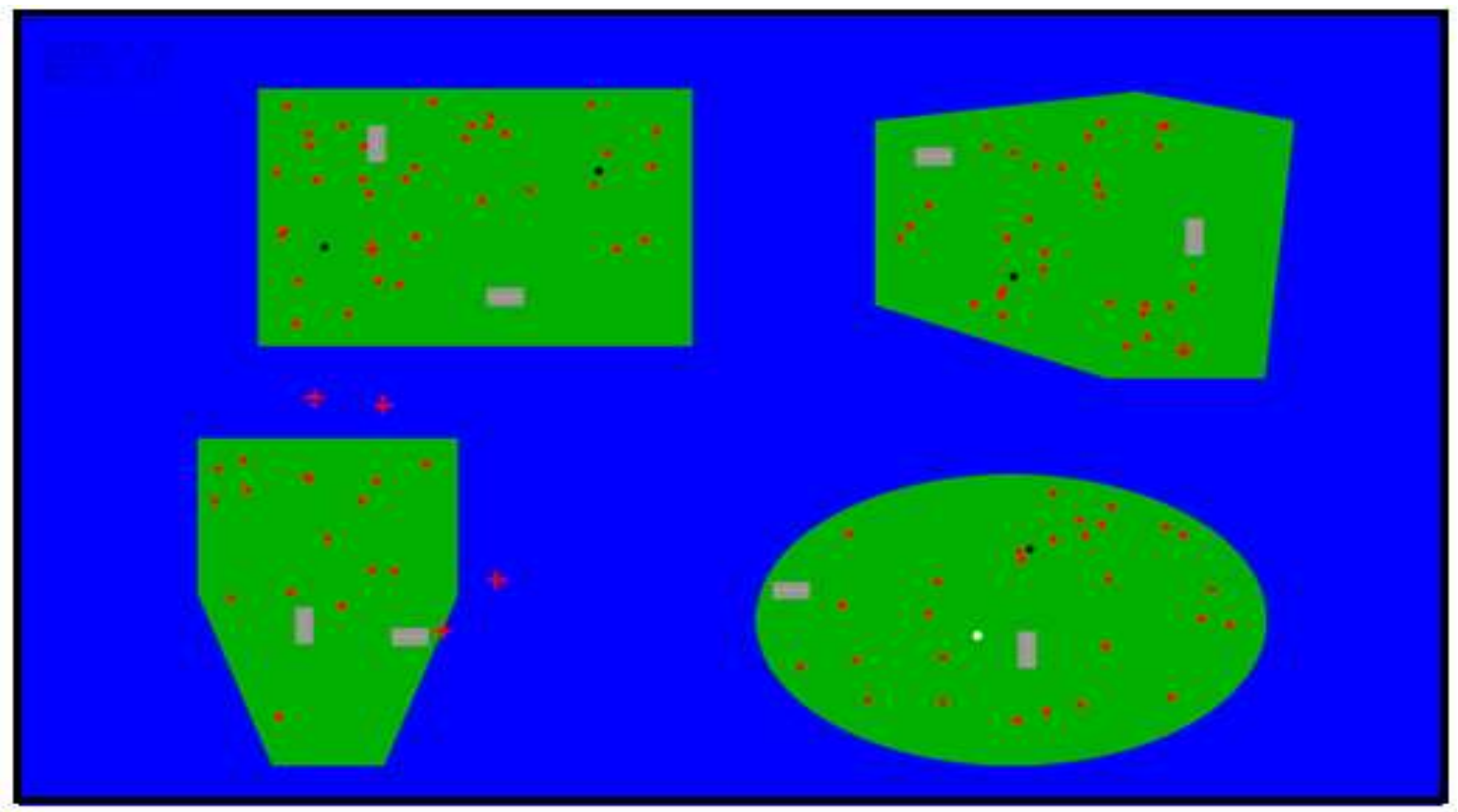

Fonte: Autores (2021).

Todas as simulações computacionais realizadas mostraram que, no caso de uma pandemia real, a primeira medida a ser adotada é evitar a circulação de pessoas. Assim, fechar aeroportos é uma medida sanitária de extrema urgência. A Figura 11 mostra a simulação de um processo de contaminação interna com um patógeno, com os aeroportos fechados, em relação ao local onde foi iniciado todo o processo. 
Figura 11. Simulação da propagação da pandemia com fechamento dos aeroportos.

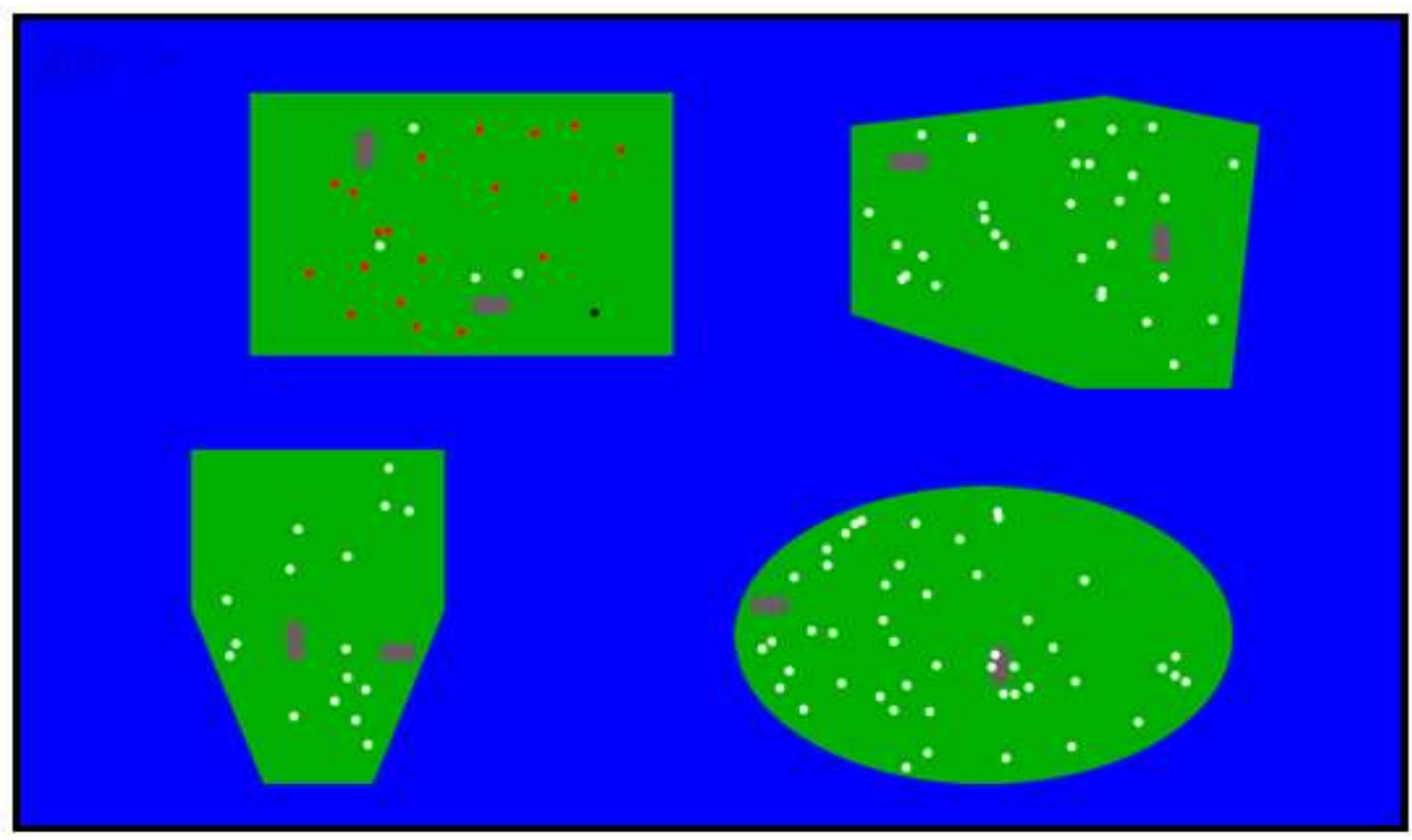

Fonte: Autores (2021).

\section{Resultados e Discussão}

Quando se estuda Data Science, o MS Excel constitui-se uma ferramenta computacional importante na análise de dados epidemiológicos. Com ele, é possível avaliar qual função matemática melhor se ajusta ao conjunto dos dados estatísticos. No presente trabalho foram utilizadas as funções potência, exponencial e polinomial. As Figuras 12 , 13 e 14 mostram respectivamente, os ajustes dos dados às funções potência, exponencial e polinomial aos dados do COVID-19 no Brasil. Sem entrar em detalhes estatísticos, pois, não é tema de discussão no ensino médio, o valor de $\mathrm{R}^{2}$ (coeficiente de determinação) foi alto para os respectivos ajustes (Figuras 12, 13 e 14). Assim, quanto maior o valor de $\mathrm{R}^{2}$, melhor será o ajuste da curva aos dados analisados. Então, a função polinomial de sexta ordem (grau do maior polinômio) teve excelente ajuste em relação aos dados avaliados (Figura 14).

Figura 12. Ajuste da função potência aos dados do COVID-19 no Brasil.

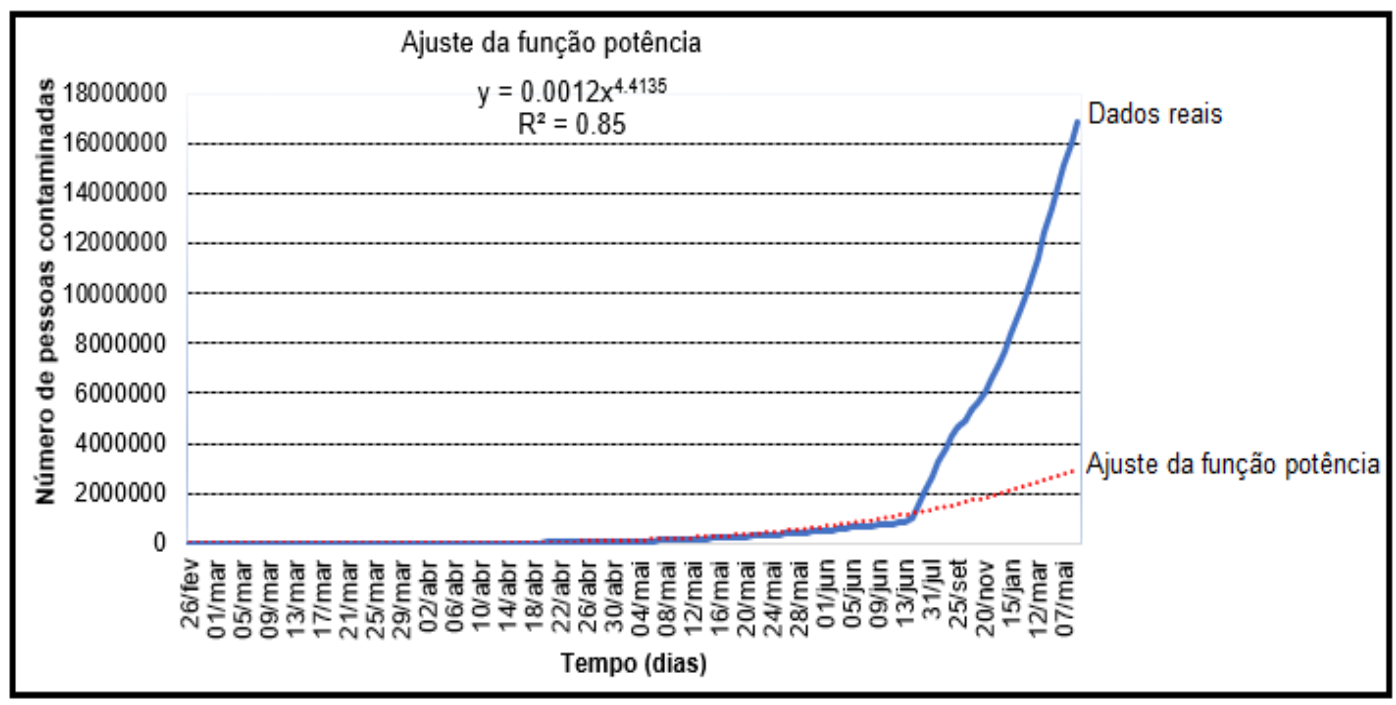

Fonte: Autores (2021). 
Figura 13. Ajuste da função exponencial aos dados do COVID-19 no Brasil.

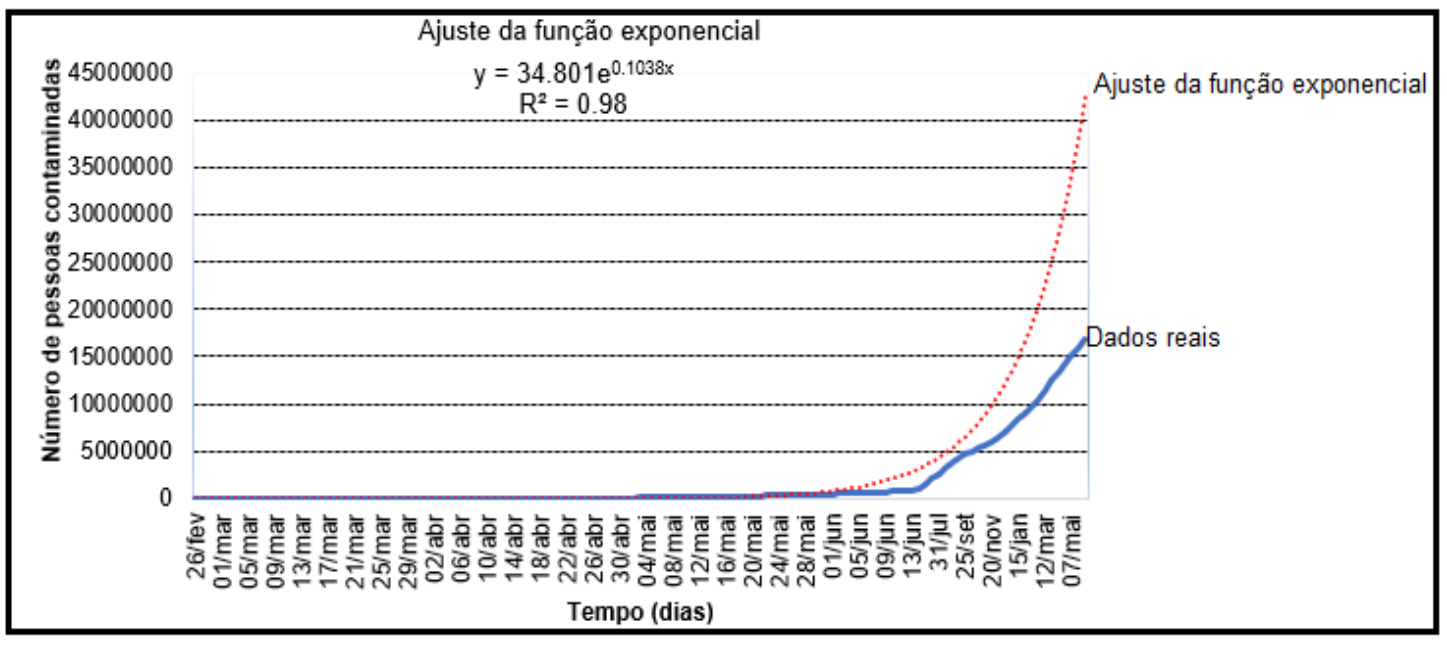

Fonte: Autores (2021).

Figura 14. Ajuste da função polinomial aos dados do COVID-19 no Brasil.

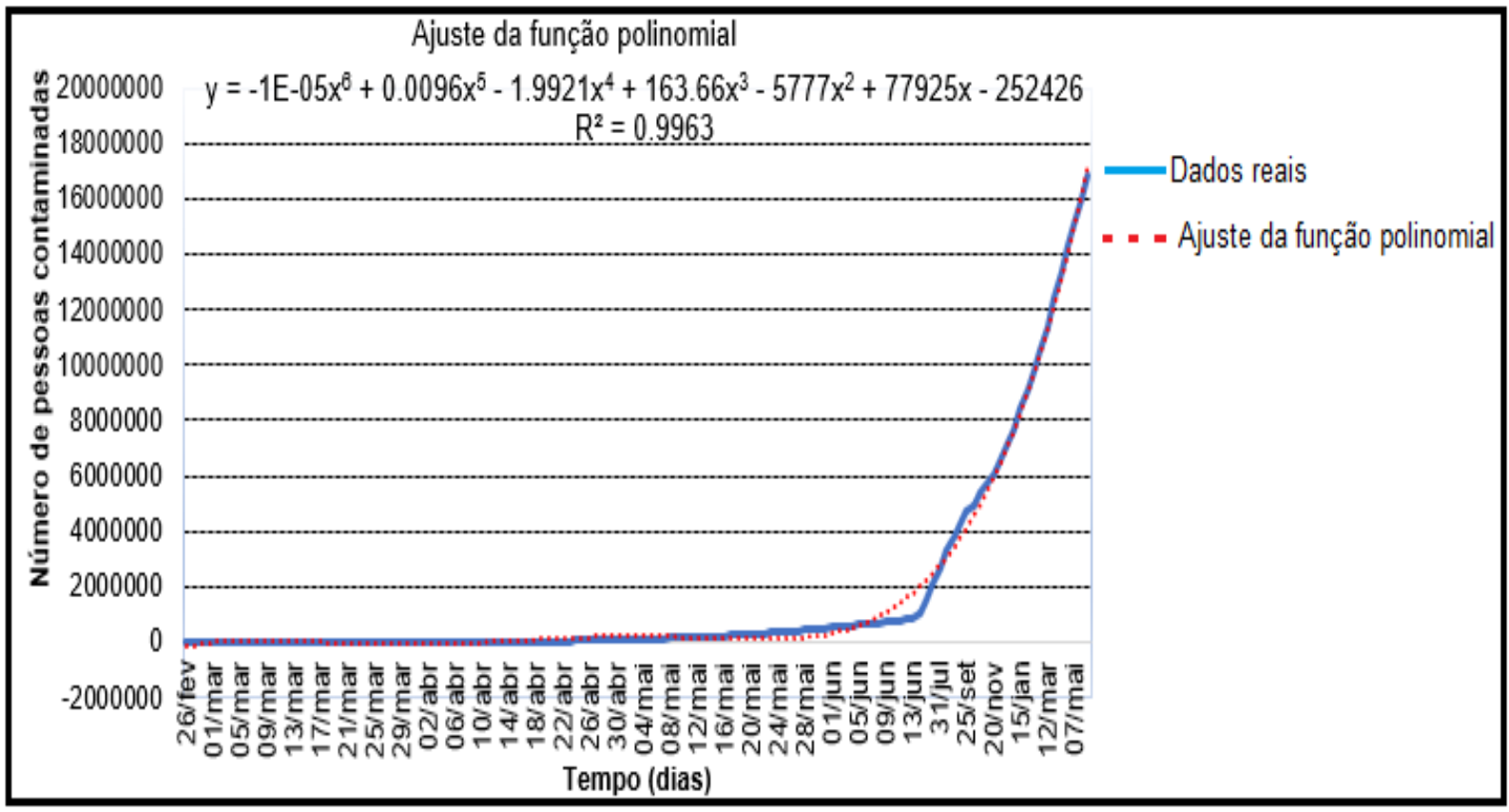

Fonte: Autores (2021).

A Figura 12 mostra que a função potência perde aderência aos dados quando o número de pessoas contaminadas cresce abruptamente, tendendo para um crescimento exponencial (Figura 13). Na verdade, por mais poder de contaminação que um determinado patógeno possa ter, em nenhum evento pandêmico, o número de pessoas contaminadas crescem indefinidamente (Figura 13), pois, atenuadores sistêmicos atuam rapidamente para evitar o aumento descontrolado do número de doentes e mortos. De acordo com Silva (2018), os atenuadores sistêmicos são primordiais para se obter controle populacional.

Por exemplo, com o tempo, o poder natural de infecção do vírus diminui, e aqueles que sobreviveram serve de barreira à proliferação do patógeno, evitando que outros indivíduos sejam contaminados. Também, o respeito às normas de contenção sanitária, tais como, o uso de máscaras, distanciamento social e isolamento social, ajudam a diminuir o processo de crescimento do número de pessoas contaminadas com o COVID-19. A Figura 13 mostra a simulação de como seria o 
crescimento exponencial onde foi considerado que nenhuma medida de contenção foi adotada para atenuar a propagação do vírus.

Matematicamente, o crescimento exponencial (Figura 13) do número de pessoas contaminadas serve como elemento indicador para mostrar o quão rapidamente é a propagação do patógeno na população, casos medidas emergenciais de contenção não forem adotadas pelos serviços de Vigilância Sanitária. Tais medidas são fundamentais para evitar números elevados de morte na população (Silva \& Filho, 2021a). Modelos matemáticos de crescimento geométrico podem ser utilizados para estudar a maneira como o COVID-19 se propaga numa população (Aluko, 2020). Estudos de modelo exponencial no ensino médio ajudam os alunos a compreender a propagação de um patógeno numa dada população (Bush, et al., 2015).

Todo modelo matemático de crescimento populacional, para ser o mais realista possível com os dados analisados, deve conter os elementos de amortecimento que tem a finalidade de evitar tendências para o infinito. Os modelos matemáticos mais sofisticados, como os de Verhulst e Gompertz, por exemplos, têm valores de saturação máxima denominados de carga máxima de suporte (Silva \& Filho, 2021b). No caso de estudos epidemiológicos, por exemplo, a carga máxima de suporte pode ser o número de leitos hospitalares de um dado país.

Segundo dados fornecidos pela Associação de Medicina Intensiva Brasileira (AMIB), o Brasil possui, aproximadamente, 45.848 (AMIB, 2020) leitos de UTI. Com base nos ajustes dos dados às funções matemáticas de crescimento (Figuras 12, 13 e 14), rapidamente, os leitos de UTI seriam ocupados. Tais resultados mostram o quanto o número de pessoas contaminadas cresce rapidamente durante um evento pandêmico. Isso causaria um número elevado de mortes, pois, pessoas que necessitassem de atendimento de urgência e emergência ficariam desprovidas de tais serviços. É terrivelmente devastador para uma nação, atingir a carga máxima de suporte hospitalar durante um evento pandêmico.

No caso da Figura 14, observar-se ajuste quase que perfeito aos dados avaliados. Isso aconteceu em decorrência da função polinomial estudada (Figura 14) possuir naturalmente elementos de amortecimento, pois, à medida que o grau do polinômio decresce, seus coeficientes absolutos aumentam, resultando assim, numa atenuação espontânea com elevada aderência da curva aos dados analisados. Sendo assim, a função polinomial pode ser facilmente estudada na escola como ferramenta indispensável para se avaliar o número de pessoas contaminadas durante um evento pandêmico.

Hoje, é notório o fato de que muitas crianças, adolescentes, jovens e adultos utilizam intensamente os jogos digitais. Mas, fica a pergunta: os jogos digitais podem ser utilizados como um recurso didático em sala de aula? É mister o fato de que os jogos digitais têm a finalidade de entretenimento e recreação, mas também pode ser eficientemente utilizado como um novo conteúdo educacional. Um trabalho interessante realizado por Rajić e Tasevska (2019) mostrou que a utilização de jogos digitais em sala de aula é um recurso didático importante para motivar os alunos a dominar o conteúdo estudado. Assim, durante o planejamento escolar, o professor pode propor a criação e apresentação de diferentes conteúdos pedagógicos através da utilização de jogos digitais. Segundo Rajić e Tasevska (2019), “o jogo como um componente chave do desenvolvimento infantil e sua aprendizagem ganhou um lugar de destaque nas formas modernas de educação, aprendizagem e ensino. Nessa era digital moderna, foram desenvolvidos tipos de jogos digitais que respondem cada vez mais ao mundo das crianças e dos jovens. Os jogos contribuem para a aprendizagem espontânea, interatividade e dinâmica, bem como para a adoção funcional de novos conteúdos". Com o Construct 2 da Scirra, por exemplo, é possível criar diversos jogos digitais interessantes.

A versão free do programa de jogos Construct 2 da Scirra é uma ferramenta didática importante que pode ser facilmente utilizada em sala de aula. O programa foi criado principalmente para o desenvolvimento de jogos $2 \mathrm{D}$. O objetivo foi abrir as portas da criação de jogos para todos, apresentando a criação de jogos de uma forma visual, intuitiva e educativa. Decorrente disso, o Construct 2 pode ser usado para simular diversos eventos, inclusive mostrar de forma intuitiva como acontece a contaminação de pessoas durante uma pandemia. Considerando as Figuras 6 a 11, pode-se observar a importância 
dos desenhos criados pelo jogo digital no entendimento de como ocorre a contaminação de pessoas durante a pandemia do COVID-19.

As Figuras 12, 13 e 14 mostram que, se medidas de contenção não forem adotadas pelos órgãos de Vigilância Sanitária, o número de pessoas contaminadas cresce abruptamente com o tempo. Semelhantemente, as Figuras 6 a 11 mostram que o número de pessoas contaminadas aumenta consideravelmente com o passar do tempo, quando não existem medidas de contenção do COVID-19. Por outro lado, a Figura 11 mostra a simulação de um evento onde houve medida de contenção com fechamento de aeroportos, deixando o vírus restrito apenas a uma região específica.

Ao fazer a conexão entre as imagens do jogo (Figuras 6 a 11) e as funções de crescimento (Figuras 12, 13 e 14), o aluno terá uma compreensão mais clara da gravidade real da pandemia do COVID-19, e será um importante agente educativo na divulgação das medidas básicas de contenção do patógeno.

\section{Considerações Finais}

Vivemos na era da informação, em que as pessoas têm acesso a dados e conhecimentos estatísticos de forma cada vez mais fácil e rápida, fazendo com que, muitas vezes, se tenha a necessidade de entender e interpretar corretamente essas informações. Nesse contexto, o professor de matemática tem função importante dentro do processo ensino-aprendizagem, pois ele é o elemento motivador, com atribuições específicas de criar um ambiente onde haja estímulos para a compreensão de dados estatísticos, sem a necessidade de aplicação subjetiva de fórmulas que estejam totalmente desconectadas de sua contextualização. Um ensino de matemática baseado apenas em aplicação de fórmulas é altamente ineficiente e desmotivador. Assim, o entendimento da linguagem matemática é de suma importância no processo ensino-aprendizagem. No geral, os estudantes brasileiros possuem grande ojeriza à matemática. Isso necessita de discussões mais acuradas dos fatos visando encontrar soluções, para que o ensino da matemática seja mais próximo possível do cotidiano dos alunos. A matemática é uma disciplina que pode ser utilizada em sala de aula como elemento motivador no processo ensino-aprendizagem, de forma prática e estimulante.

A contextualização é crucial para os alunos entenderem a importância do ensino na sua vida cotidiana. Analisando o ensino de matemática no Brasil, observa-se que a teoria se encontra bastante descontextualizada do dia a dia dos alunos e poucas quantidades de aulas referentes a conteúdos práticos. Geralmente, quando essas aulas são ministradas, contém grande quantidade de fórmulas aplicadas subjetivamente, que dificultam a aprendizagem dos alunos. Assim, em qualquer ensino de matemática, a introdução de fórmulas deve ajudar na interpretação dos dados que são apresentados em tabelas, gráficos e relatórios. Entretanto, o que se observa na prática, em sala de aula, são alunos que não conseguem ou têm muita dificuldade na decodificação de tabelas e gráficos para descrever relações entre as partes e o todo. A alfabetização matemática ou letramento matemático é um novo desafio para os professores de matemática, mas pode ser uma estratégia de ensino que auxilie a leitura e a interpretação de dados apresentados em tabelas, gráficos e relatórios.

As funções potência, exponencial e polinomial apresentaram diferentes tipos de ajustes aos dados do número de pessoas contaminadas com o COVID-19 no Brasil. A função polinomial apresentou melhor ajuste aos dados do que às funções potência e exponencial. As funções potência, exponencial e polinomial podem ser utilizadas como ferramentas didáticas no ensino médio para se entender o comportamento do crescimento do número de pessoas contaminadas durante uma pandemia.

O simulador pandêmico na forma de um jogo digital contribuiu significativamente para entender como ocorre a contaminação com o COVID-19 numa dada população.

Relacionar as funções de crescimento com o simulador pandêmico foi uma estratégica didática importante para ajudar no entendimento holístico da pandemia do COVID-19. 
Os estudos matemáticos de qualquer endemia ou pandemia devem ser a primeira medida não farmacológica para combater a disseminação de uma doença numa dada população. Baseado nesses estudos, os órgãos sanitários devem adotar medidas de contenção para evitar que o patógeno seja facilmente transmitido e cause números elevados de morte dentro da população.

Contextualizar o ensino de matemática na escola com dados reais é uma via de aprendizado que desperta grande interesse dos alunos. A interação entre conhecimentos básicos de ciência da computação, matemática e data science devem compor o currículo do ensino médio das escolas do Brasil. Não se pode admitir um ensino de matemática na escola descontextualizado da realidade dos alunos. Cada professor pode inovar na ministração de suas aulas, usando dados do cotidiano presentes em diferentes áreas do conhecimento. Os estudos de funções matemáticas, por exemplo, podem e devem ser ensinados usando a imensa quantidade de dados existentes na rede de internet. Isso daria mais significado aos estudos teóricos das funções matemáticas. É importante sim, que toda a teoria seja apresentada com os respectivos algebrismos, porém, com significado de aplicação no dia a dia do aluno. $\mathrm{Na}$ verdade, isso dará força no combate contra a velha métrica argumentativa alunesca: "isso vai servir para que na minha vida?"

Sugerimos para trabalhos futuros, a utilização de dados epidemiológicos acoplados diretamente a um aplicativo computacional, com a finalidade de simular o crescimento da curva pandêmica em função do tempo.

\section{Agradecimentos}

Agradecemos ao Instituto Federal de Educação Ciência e Tecnologia de Brasília pelo apoio financeiro.

\section{Referências}

Aluko, E. (2020). Modelling the COVID-19 epidemic as a geometric progression application to Nigeria, United Kingdom \& other select countries. https://www.researchgate.net/publication/342063367_Modelling_the_COVID19_Epidemic_As_a_Geometric_Progression_Application_to_Nigeria_United_K ingdom_Other_Select_Countries.

Associação de Medicina Intensiva Brasileira (AMIB). (2020). AMIB apresenta dados atualizados sobre leitos de UTI no Brasil. https://www.amib.org.br/fileadmin/user_upload/amib/2020/abril/28/dados_uti_amib.pdf.

Brasil (1999). Ministério da Educação. Secretaria de Educação Média e Tecnológica. Parâmetros Curriculares Nacionais (PCN)-Ensino Médio. http://portal.mec.gov.br/setec/arquivos/pdf/BasesLegais.pdf.

Brasil (2021a). Ministério da Educação. Base Nacional Comum Curricular. http//basenacionalcomum.mec.gov.br/.

Brasil (2021b). Ministério da Saúde do Brasil. Painel de casos de doença pelo coronavírus 2019 (COVID-19) no Brasil. https://covid.saude.gov.br/.

Britannica (2021). Function mathematics. https://www.britannica.com/science/function-mathematics.

Bush, S. B., Gibbons, K., Karp, K., \& Dillon, F. (2015). Epidemics, exponential functions, and modeling. Mathematics Teaching in the Middle School, 21 (2), 90-97. https://doi.org/10.5951/mathteacmiddscho.21.2.0090

Cavalcante, J. R. (et al.). (2020). COVID-19 no Brasil: evolução da epidemia até a semana epidemiológica 20 de 2020. Revista Epidemiologia e Serviços de Saúde, 29 (4), e2020376. https://doi.org/10.5123/S1679-49742020000400010

Carvalho, C., \& Solomon, Y. (2012). Supporting statistical literacy: What do culturally relevant/realistic tasks show us about the nature of pupil engagement with statistics? International Journal of Educational Research, 55, 57-65. https://doi.org/10.1016/j.ijer.2012.06.006

Curcio F. R. (1987). Comprehension of mathematical relationship expressed in graphs. Journal for Research in Mathematics Education, 18 (5), $382-393$. https://doi.org/10.2307/749086

Denbel, D. G. (2015). Functions in the secondary school mathematics curriculum. journal of education and practice, 6 (1).

Donovan, M. S., \& Bransford, J. D. (2005). How Students Learn: History, Mathematics, and Science in the Classroom. Committee on How People Learn, A Targeted Report for Teachers. Division of Behavioral and Social Sciences and Education. National Research Council of the National Academies. The National Academies Press. Washington, D.C.

Freire, P. (2019). Educação como prática da liberdade. Brasil: Paz \& Terra.

Gal, I. (2002). Adult statistical literacy: Meanings, components, responsibilities. International Statistical Review, 1 (70), 1-25. https://doi.org/10.2307/1403713 
Gros, B. (2007). Digital games in education: the design of games-based learning environments. Journal of Research on Technology in Education, 40 (1), 2338.

Griffiths, J. P. (2020). Can mathematical modelling solve the current Covid-19 crisis? BMC Public Health, 20 (551), 2-3. https://doi.org/10.1186/s12889-02008671-z

Grus, J. (2016). Data Science do zero: primeiras regras com o Python. Alta Books.

Kataoka, V. Y. (et al.). (2011). A educação estatística no ensino fundamental II em Lavras, Minas Gerais, Brasil: avaliação e intervenção. Revista latino americana de investigácion en matemática educativa, 14 (2), 233-263.

Krause, S. J., Waters, C., \& Stuart, W. J. (2016). Effect of contextualization of content and concepts on students' course relevance and value in introductory materials classes. In: Asee's 123RD Annual Conference \& Exposition, New Orleans, LA, June 26-29, 2016. American Society for Engineering Education. Paper ID \#14943.

Leinhardt, G., McCarthy Young, K., \& Merriman, J. (1995). Commentary: Integrating professional knowledge: The theory of practice and the practice of theory. Learning and Instruction, 5, 401-408. https://doi.org/10.1016/0959-4752(95)00025-9

Meneghetti, R. C. G., \& Redling, J. P. (2012). Tarefas alternativas para o ensino e a aprendizagem de funções: análise de uma intervenção no ensino médio. Bolema, 26 (42A), 193-229. https://doi.org/10.1590/S0103-636X2012000100010

Nacarato, A. M., \& Lopes, C. E. (2009). Escritas e leituras na educação matemática. Autêntica.

Pinker, S. (1990). A theory of graph comprehension. In R. Freedle, Artificial intelligence and the future testing. Hillsdale, NJ: Erlbaum. https://www.researchgate.net/publication/213802830_A_theory_of_graph_comprehension.

Rajić, S. B., \& Tasevska, A. (2019). The role of digital games in children's life. Иноваиије у настави, 32 (4), 97-108. 10.5937/inovacije1904097R

Reis, R. F. (et al.). (2020a) Características e projeções da pandemia Covid-19 no Brasil, Minas gerais e Juiz de Fora. Nota Técnica 01 - PGMC/UFJF. https://www2.ufjf.br/pgmc/wp-content/uploads/sites/236/2020/03/nt01pgmc-30-03-2020.pdf.

Reis, R. F. (et al). (2020b). Características e projeções da pandemia Covid-19 no Brasil, Minas gerais e Juiz de Fora. Nota Técnica 02 - PGMC/UFJF. https://www2.ufjf.br/pgmc//files/2020/03/nt02_covid19_pgmc_ufjf1.pdf.

Reyes, J. D., Insorio, A. O., Ingreso, M. L. V., Hilario, F. F., \& Gutierrez, C. R. (2019). Conception and application of contextualization in mathematics education. International Journal of Educational Studies in Mathematics, 6 (1), 1-18.

Riyapan, P., Shuaib, S. E., \& Intarasit, A. (2021). A Mathematical model of COVID-19 Pandemic: a case study of Bangkok, Thailand. Computational and Mathematical Methods in Medicine, 2021, 1-11. https://doi.org/10.1155/2021/6664483.

Shah, P., \& Carpenter, P. A. (1995). Conceptual limitations in comprehending line graphs. Journal of Experimental Psychology, 124 (1), $43-61$. https://doi.org/10.1037/0096-3445.124.1.43

Silva, C. M. (2018). Estudo qualitativo de populações bíblicas usando o modelo de Verhulst. Origem em Revista, 1, 9-14.

Silva, C. M., \& Filho, G. F. C. (2021a). A progressão geométrica e o novo coronavírus no Brasil. Revista Mais Educação, 4 (1), 380-392.

Silva, C. M., \& Filho, G. F. C. (2021b). Modelagem matemática usando os números de casos do sars-cov-2 (covid-19) no Brasil. Revista Mais Educação, 4 (1), 946- 961 .

Tufte, E. R. (1983). The visual display of quantitative information. Graphics Press.

Viana, M. (2020). BBC explora questões sobre a matemática do futuro. https://impa.br/noticias/bbc-explora-questoes-sobre-a-matematica-do-futuro/.

Wallman, K. K. (1993). Enhancing statistical literacy: enriching our society. Journal of the American Statistical Association, 88 (421), 1-8. https://doi.org/10.2307/2290686

World Health Organization (WHO). (2020a). Pneumonia of unknown cause-China. Disease outbreak News. https://www.who.int/emergencies/diseaseoutbreak-news/item/2020-DON229.

World Health Organization (WHO). (2020b). Statement on the second meeting of the International Health Regulations (2005) Emergency Committee regarding the outbreak of novel coronavirus (2019-nCoV). https://www.who.int/news/item/30-01-2020-statement-on-the-second-meeting-of-the-internationalhealth-regulations-(2005)-emergency-committee-regarding-the-outbreak-of-novel-coronavirus-(2019-ncov).

World Health Organization (WHO). (2020c). WHO announces COVID-19 outbreak a pandemic. https://www.euro.who.int/en/health-topics/healthemergencies/coronavirus-covid-19/news/news/2020/3/who-announces-covid-19-outbreak-a-pandemic.

World Health Organization (WHO). (2020d). Coronavirus disease 2019 (COVID-19) Situation Report- 88. https://www.who.int/docs/defaultsource/coronaviruse/situation-reports/20200417-sitrep-88-covid-191b6cccd94f8b4f219377bff55719a6ed.pdf?sfvrsn=ebe78315_6.

Zirawaga, V. S., Olusanya, A. I., \& Maduku, T. (2017). Gaming in education: using games as a support tool to teach history. Journal of Education and Practice, 8 (15), 55-64. 